\title{
EL DISCO ESTÁ BESADO POR JUSTIN, LA NOVELA YA ESTÁ LEÍDA: A PROPÓSITO DE LAS CONSTRUCCIONES RESULTATIVAS CON ESTAR
}

\author{
Ma Antonia Martínez Linares \\ Universidad de Alicante \\ Grupo EPA \\ antonia.martinez@ua.es
}

Recibido: 16/06/2015

Aceptado: 02/09/2015

\begin{abstract}
Resumen
Este trabajo tiene por objeto indagar sobre dos aspectos de las construcciones resultativas formadas por un participio y el verbo estar: por un lado, la vinculación de estas construcciones con el concepto de 'estado resultante'; por otro lado, la existencia de construcciones resultativas de sentido atributivo que incorporan complementos referidos al agente y/o no están formadas por verbos que incluyan en su estructura léxica un estado resultante. El examen muestra que "estado resultante" se usa al menos con dos sentidos que se relacionan asimismo con dos tipos de construcciones resultativas: unas de sentido atributivo o cualitativo, más comúnmente reconocido, otras con un sentido "de fase" más temporal, asociado a la interpretación del "aspecto perfecto". Muestra igualmente que las complementaciones agentivas contribuyen a formar el sentido cualitativo propio de las construcciones atributivas y que ninguna de estas dos clases de construcciones se restringe a verbos que incluyan en su estructura léxica un "estado resultante" ni su formación puede explicarse tomando como base las clases léxico-aspectuales de predicados o rasgos exclusivamente gramaticales sin tomar en consideración aspectos contextuales y pragmáticos.

PALABRAS CLAVE: Estado resultante, construcción resultativa, aspecto perfecto, complementaciones agentivas, adverbio de fase.
\end{abstract}

\begin{abstract}
This study focuses on two aspects of estar+past participle resultative constructions. On the one hand, the paper analyses the concept of 'resultant state' and its relevance to the analysis of these constructions. On the other hand, this work examines estartpast participle constructions that have an attributive meaning but are not built with a change of state verb and/or include an agentive $b y$-phrase. The study shows that there are at least two senses in which the term "resultant state" is used and that those senses are also related to two types of resultative constructions: one of them has an attributive or qualitative meaning, the other one has a more temporal "phasal" sense, related to the meaning of "perfect aspect". The study also reveals that none of these two types of constructions is restricted to verbs that lexicalize a "resultant state" and cannot be explained by using exclusively grammatical features or aspectual classes; it is also necessary to take contextual and pragmatic factors into account.
\end{abstract}

KEY WORDS: Resultant state, estar+Pparticiple resultative construction, perfect aspect, agentive complements, phasal adverb.

\section{Introducción}

Tanto la posibilidad de que un verbo admita una construcción de participio con estar como las peculiaridades semánticas y sintácticas de estas construcciones se han venido explicando, fundamentalmente, tomando como base las propiedades léxico-aspectuales de los verbos. 
La anomalía de *Mi hijo está amado, por ejemplo, se ha justificado por el carácter estativo, imperfectivo, no acotado de amar (Marín, 2004: 26; De Miguel, 2001; Fernández et al., 2002: 392). En cambio, la buena formación de La ciudad está destruida o La puerta está abierta se debería a que destruir y abrir son verbos que denotan un cambio e incluyen en su estructura léxica un estado resultado. Asimismo, se han vinculado a distinciones de índole aspectual las diferencias entre construcciones como La ciudad está destruida, que rechazaría un complemento agente con por (*por los romanos), y El garaje está vigilado por un guarda, que sí admitiría una complementación agentiva y que, frente a la anterior, estaría formada por un verbo "imperfectivo" (Gómez Torrego, 1988: 188), "atélico" (Jurado, 2000: 186), de "actividad" (Yllera, 1999: 3430), un verbo que, en definitiva, ni exige "conceptualmente un principio y un fin" (Bosque, 1999: 292) ni codifica un cambio.

No obstante, también se ha señalado que aún quedan muchas cuestiones por resolver en torno a estas construcciones; que no todo parece explicarse de forma satisfactoria partiendo de propiedades aspectuales, a menudo, por lo demás, difícilmente acotables. Y, en efecto, conforme se va profundizando en el análisis de las construcciones de participio con el verbo estar, no solo parece necesario matizar las clases que se distinguen en este grupo y las características que se les atribuyen, sino también considerar entre los condicionantes de la formación de determinadas construcciones factores que no son estrictamente de índole léxico-aspectual.

Este trabajo tiene por objeto indagar algo más en las propiedades y los condicionamientos de algunas de estas construcciones; en particular de las que, para diferenciarlas de las "inversiones de locación" - como La ciudad está rodeada por montañas- y de las "pasivas no resultativas" (Jurado, 2000) ${ }^{1}$-como El garaje está vigilado (por un guarda)-, suelen catalogarse como "(estativas) resultativas" (Fernández et al., 2002: 391), "pasivas de resultado o resultante" (Mendikoetxea, 1999: 1623; Jurado, 2000), "resultativas no pasivas" o "resultativas puntuales" (Conti, 2004), "pasivas de carácter perfectivo-estativo" (Gómez Torrego, 1988: 188) o "pasivas adjetivas"2; en definitiva, las del tipo La ciudad está destruida, que vienen a coincidir con las construcciones a las que Kratzer (2000) o Maienborn (2009) entre otros atribuyen una lectura "target state" y a las que en adelante me referiré simplemente como "resultativas". Con ese fin, se recordarán en primer lugar las características semánticas y los condicionamientos que, de forma más general, se les han venido asociando para, posteriormente, analizar dos aspectos que se han ido revelando como especialmente problemáticos ${ }^{3}$ en el análisis de estas construcciones: por un lado su vinculación con el concepto de 'estado resultante' y los sentidos que explícita o implícitamente se asocian al término; por otro lado, la existencia de construcciones resultativas que incluyen complementos relacionados con el "agente" y/o se forman con verbos que no incorporan en su estructura léxica un estado resultante. El análisis permitirá, en primer lugar, mostrar los varios sentidos que

1 También llamadas "pasivas imperfectivas" (Gómez Torrego, 1988: 188) o "pasivas de estado" (Conti, 2004: 27). Se consideran formadas con verbos de "actividad", con una estructura eventiva simple, que no incorpora un cambio de estado o un estado resultado; por lo que respecta al significado, se les atribuye la denotación de un presente extendido (alguien vigila el garaje, Dios gobierna el mundo), de una acción que se presenta como coexistente con el estado descrito por el participio (Bosque, 1999: 292) y requiere la actuación continua del agente para seguir manteniendo el estado.

2 Poniéndolas así en relación, al menos en parte, con las pasivas adjetivas del inglés o del alemán.

3 Omito las discusiones en torno a la pasividad de estas construcciones, cuyo carácter problemático queda ya patente en las denominaciones que se utilizan para identificarlas. 
subyacen a "estado resultante" y los diferentes tipos de construcción, vinculados con esos sentidos, que se han mezclado a menudo como si formaran una sola clase: las construcciones que configuran una interpretación atributiva y las que tienen un sentido de "fase". En segundo lugar, pondrá de manifiesto la relevancia que adquieren en la viabilidad de las construcciones resultativas de sentido atributivo tanto las complementaciones referidas al agente -compárese, por ejemplo, ¿?El edificio está construido y El edificio está construido por Мoneo- como, en general, factores que no son estrictamente aspectuales.

\section{Sobre las construcciones resultativas}

Las construcciones resultativas del tipo Las puertas están cerradas, La ciudad está destruida, se han descrito, al igual que sus equivalentes en otras lenguas ${ }^{4}$, como construcciones "estativas", de "caracterización", en cuanto que denotan una propiedad o estado 5 del sujeto resultante del evento designado por el verbo; así, las oraciones antes mencionadas expresarían que el sujeto se encuentra en el estado descrito por el participio como consecuencia de haberse realizado previamente la acción de destruir o cerrar; estarían pues, de conformidad con la Academia, "en correspondencia con" (RAE, 2009: 2215) La ciudad ha sido destruida, Las puertas han sido cerradas, pero, mientras estos tiempos compuestos de la pasiva con ser focalizarían la acción que da lugar al estado, en la construcción resultativa la actividad previa estaría totalmente "ausente en la interpretación" (Fernández et al., 2002: 391), habría sido "desfocalizada por completo" (Conti, 2004: 38), de manera que, "according to the traditional view" (Gehrke y Sánchez, 2014: 188), también el "argumento externo", el "actor", vinculado a esa actividad anterior, "is truly missing" (Kratzer, 2000: 391), estaría "completely absent" (Gehrke, 2012: 187); por tanto, esta construcción resultativa de carácter atributivo no admitiría, o al menos "resistiría", "tendería a rechazar" (Mendikoetxea, 1999: 1624; Bosque, 1999: 292), la expresión de un complemento agentivo con por, que se asocia a la acción, o la incorporación de complementos de finalidad o adverbios de manera que impliquen la existencia de un agente vinculado a la acción anterior: * La ciudad está destruida por los romanos, *La casa está construida por los albañiles/por los hermanos/por obreros mexicanos, *La cena ya está preparada por un cocinero profesional se han considerado anómalas por incluir complementos agentivos (Mendikoetxea, 1999: 1624; Conti, 2004: 28; Hengelved, 1986: 411; Bruhn de Garavito y Valenzuela, 2008: 329), igual que *El cuadro está pintado por Leonardo para agradar al marido de Mona Lisa por dar cabida a un complemento de finalidad (De Miguel, 2001), o *Emilio estaba atado violentamente al árbol (Conti, 2004: 38) por expresar un complemento de "manera" relacionado con la existencia de un "Actor". En definitiva, estas construcciones de participio con estar se han caracterizado como las oraciones copulativas con adjetivos perfectivos, de las que también se ha dicho que

\footnotetext{
4 Como las pasivas estativas o resultativas en alemán, que, a diferencia de las pasivas eventivas, no se combinan con el auxiliar werden sino con sein (Bosque, 2014: 42; Gehrke, 2012: 185; Maienborn, 2009: 38; Kratzer, 2000: 385).

5 No entro en la especificación de los conceptos de 'estado', 'cualidad', 'propiedad', que a veces se utilizan como si fueran equivalentes. Como indica Bosque (1990: 185), "es razonable afirmar que los adjetivos perfectivos representan estados alcanzados por las entidades de las que se predican, pero es discutible que representen cualidades suyas", esto es "características o rasgos definitorios". Sin embargo, para Conti (2004: 39) en Este cuadro está pintado por Velázquez el predicado expresa una propiedad inherente del sujeto paciente.
} 
expresan "el estado subsecuente al término de las acciones que las producen" (Fernández Leborans, 1999: 2430), pero sin pensar necesariamente en los procesos que lo llevan a cabo (Bosque, 1990: 186). De hecho, para Vázquez et al. (2000: 136) o Fernández et al. (2002: 392), por ejemplo, están contentos, están limpias, serían construcciones resultativas, alternativas a están limpiadas, están contentados $^{6}$; Conti (2004: 39) cataloga La casa ya está limpia como "resultativa puntual" que "focaliza la fase de estado asociada al Paciente", al igual que Emilio estaba atado al árbol; para Jiménez Peña y Rodriguez Sellés (2002: 227) El sofá está sucio sería una variante resultativa de Josep ha ensuciado el sofá, del mismo modo que La puerta está abierta o Las coles de Bruselas están congeladas lo serían de Josep ha abierto la puerta/ha congelado las coles de Bruselas; en opinión de Mendikoetxea (1999: 1624), La ciudad está destruida tendría un significado equivalente al de "construcciones copulativas <estar+adjetivo perfectivo>" como estar limpio, estar seco. Para De Miguel (2001), por último, tanto en el caso del enunciado La puerta está abierta como en el de Este cuadro está pintado en la pared fpor Leonardo "ci troviamo di fronte ad una struttura attributiva che esprime un risultato".

En lo que atañe a los condicionamientos, el rasgo más reiterado como requisito para la formación de estas construcciones ha sido, sin duda, que el verbo base del participio incluya como parte de su contenido léxico la denotación de un "estado resultante" o "estado resultado". La Real Academia (2009: 2215-6) subraya a este respecto que la construcción "estar+participio" se forma con verbos que "denotan estado resultante de una acción o de un proceso" - como Las puertas están cerradas-; por consiguiente, la admitirían, a su juicio, los verbos transitivos que expresan "creación, destrucción o modificación de algo". Mendikoetxea (1999: 1623) la relaciona con verbos bieventivos, como destruir, a los que se atribuye una estructura compuesta por un evento causativo de acción y un evento resultativo de estado; desde el punto de vista de Fernández et al. (2002: 392), los verbos que posibilitan estas construcciones han de contener en su significado un "límite que coincide con el estado resultado" consecuencia del proceso de cambio designado por el verbo. En opinión de Jurado (2000: 185) la construcción requiere verbos télicos (logros y realizaciones), que denotan eventos con un final inherente y dan lugar a un "estado resultante" del cambio que se produce cuando el evento ha llegado a su culminación; de ahí, a su juicio, la gramaticalidad de La cima está alcanzada, La lección está explicada o El patio (ya) está barrido7. En términos de Gehrke (2012: 189), por citar una opinión más, "accomplishment and achievement verbs, whose internal argument undergoes a change of state and as a result is the bearer of a consequent state, are good inputs" para las construcciones equivalentes en alemán; en definitiva, como resume Bruening (2012: 10), si describen estados de las entidades, parece lógico que "a general felicity condition on their use, then, is that the semantics of the base verb be compatible with a (result) state". Por el contrario, quedarían excluidos de esta construcción, por ejemplo, los verbos que expresan "actividades en el sentido de acciones no delimitadas" (RAE, 2009: 2216) como empujar, acariciar, besar ${ }^{8}$, que no dan

6 Indican al respecto que "aunque el estado resultado suele expresarse mediante un participio, en algunos casos se requiere un adverbio o bien un adjetivo": Las habitaciones están limpias (*limpiadas) (2002: 392).

7 En este caso, comenta, la telicidad vendría dada por el patio, aunque barrer sea un verbo de actividad (Jurado, 2000: 188).

8 Besar para unos sería "semelfactivo", para otros de "actividad" o un tipo particular de verbo de "actividad" (RAE, 2009: 1700). 
lugar a un estado resultante, que no aluden a "acciones que conllevan procesos o que se caractericen por desembocar en estadios episódicos" (Bosque, 1999: 288).

Pero si bien buena parte de los textos consultados destacan como requisito habilitador el concepto de 'estado resultante' y subrayan como propiedad de la construcción resultativa la "focalización" de ese estado en detrimento del proceso que lo ha originado, lo cierto es que también llaman la atención las discrepancias sobre el sentido y la gramaticalidad de determinados enunciados, discrepancias que parecen tener su base ya en la clase aspectual del verbo y su capacidad para denotar un estado resultante, ya en la presencia o ausencia de complementos vinculados a la acción, como los de naturaleza agentiva encabezados con por $^{9}$.

\section{Sobre la telicidad, el estado resultante y la lectura resultativa}

Por lo que concierne a las diferencias de opinión relacionadas con la estructura léxicoaspectual del verbo, se ha de subrayar que, junto a construcciones resultativas prototípicas, indiscutidas, con verbos de cambio, como La ciudad está destruida, en los estudios sobre las construcciones de participio con estar se han presentado como ejemplares de este tipo otros enunciados que, cuando menos, parecen discutidos en lo que concierne a su contenido "de caracterización", atributivo, o a su "gramaticalidad" (o "aceptabilidad"); así La casa está construida ${ }^{10}$, con un verbo de creación, o El piso ya está comprado, El patio (ya) ${ }^{11}$ está barrido, La cima (ya) está alcanzada, La lección (ya) está explicada ${ }^{12}$, Las solicitudes están revisadas, con verbos que no lexicalizan un cambio, se catalogan en algunos estudios como construcciones resultativas (Jurado Salinas, 2000: 185; Gómez Torrego, 1988: 189; Conti, 2004: 38; Mendikoetxea, 1999: 1623) que atribuyen al sujeto un "estado"; otros, por el contrario, o no las interpretan como resultativas, como construcciones que predican del sujeto una característica resultante de un evento previo (Fernández et al., 2002: 392; Vázquez y Fernández, 2003: 160), o ni siquiera las consideran aceptables salvo que incluyan elementos como el adverbio modal bien o como el adverbio aspectual ya, llamativamente recurrente en los enunciados con que se ilustran las peculiaridades de las construcciones de participio con estar. Para Marín (2004: 28), por ejemplo, son "perfectamente gramaticales" El cuadro está bien pintado, La casa ya está construida, pero cataloga como "de dudosa aceptabilidad" El cuadro está pintado, La casa está construida; Jiménez Peña y Rodríguez Sellés (2002: 220) consideran "agramatical" Los platos están fregados, con un verbo que, al igual que barrer, suele catalogarse como de "actividad", pero añaden que sí resultaría aceptable con ya: Los platos ya están fregados. Desde el punto de vista de Vázquez y Fernández (2003: 160) y Fernández et al. (2002: 392), tampoco sería válida como construcción resultativa, “de

9 Sí se consideran válidos en cambio enunciados como El cuadro está pintado por Leonardo (De Miguel, 2001); El documento está firmado por Cervantes (Conti, 2004: 39) o El libro está publicado por la mejor editorial del pais (RAE, 2009: 289).

10 Para Conti (2004: 27) no resulta una construcción extraña; es una construcción aspectual de valor resultativo que no tiene sentido pasivo.

11 Incluyo ya entre paréntesis porque las mismas combinaciones aparecen con o sin ese adverbio, a menudo sin que se llame la atención sobre su incorporación al enunciado. Conti (2004: 27, 30), por ejemplo, ilustra las características de las construcciones de participio con estar utilizando enunciados como El piso ya está comprado *por mis hijos, El pastel ya está hecho.

12 Jurado las utiliza sin ya (La lección está explicada, La cima está alcanzada), pero también con ya: La cima ya está alcanzada. Parece considerar del mismo tipo El patio ya está barrido y El patio está barrido. 
caracterización", la formada con un verbo "atélico" "agentivo" como revisar: Estos aparatos están revisados, Las solicitudes están revisadas serían construcciones correctas y semejantes formalmente a las resultativas, pero no tendrían el sentido atributivo que se considera propio de las resultativas, y otro tanto afirman de La casa ya está vendida.

Hay pues discrepancias sobre la gramaticalidad de determinados enunciados originadas por los verbos que unos y otros consideran habilitados para formar una construcción resultativa, aun cuando, según se habrá podido apreciar en el anterior apartado, a todas las unidades verbales mencionadas se les haya asociado la denotación de un estado resultante; es lógico pensar que pueden ser muchas y de diversa índole las cuestiones imbricadas ${ }^{13}$ en estas discrepancias, pero considero relevante destacar que al menos parte de ellas parecen tener su origen en las interpretaciones de que es susceptible el término "estado resultante" y la imprecisión ${ }^{14}$ o la falta de definición de que adolece con frecuencia su empleo, pese al papel relevante que se le otorga en la explicación de estas -y no solo de estas- construcciones sintácticas.

\subsection{Sobre los sentidos de "estado resultante"}

"Estado resultante" (o "resultado") no es, en efecto, un término unívoco. De los estudios que se han venido citando se infiere la existencia de, cuando menos, dos sentidos que no suelen estar suficientemente diferenciados, si bien de cada uno de ellos se podrían derivar no solo condiciones distintas sobre la formación de las construcciones resultativas, sino también diferentes interpretaciones "resultativas".

El concepto de estado resultante que se desprende de los planteamientos más restricti$\operatorname{vos}^{15}$ sobre las construcciones resultativas y sus condicionamientos está relacionado ${ }^{16}$ con la noción de cambio de estado: alude a las propiedades adquiridas por una entidad como consecuencia del cambio significado por el predicado. En consecuencia, la construcción resultativa que focaliza ese tipo de estado resultante se considera propia de verbos como destruir, cortar, cerrar, que, además de denotar eventos temporalmente delimitados, implican un "argumento afectado", cambiado, y tienen, efectivamente, esa estructura léxico-aspectual bieventina integrada por un evento de cambio que afecta a los atributos de una entidad y un estado resultante de ese cambio. De conformidad con Marín (2004: 28), por ejemplo, la afectación, la modificación del objeto léxicamente especificada, resulta crucial en las construcciones de participio con estar; no solo exigirían un predicado delimitado temporalmente, sino, según sus términos, "un resultado o, cuando menos, un cambio de estado" asociado a un "argumento afectado". Igualmente para Jiménez Peña y Rodríguez Sellés (2002: 218) o para Fernández et al. (2002: 391), la viabilidad de la construcción se asocia exclusivamente a verbos como romper o cortar que denotan un cambio de propiedades que afecta a una entidad. De tal supuesto se seguiría que, por ejemplo, no se podría formar un enunciado

13 Entre ellas, las que refieren al aspecto "perfecto" y las mejoras con ya.

14 Bosque advertía hace un tiempo (1999: 288-289) que el concepto "resultado" se maneja en estas construcciones de participio "como si se tratase de una información evidente que proporciona automáticamente cada noción verbal" cuando en realidad el concepto "encierra una considerable complejidad". También Marín (2004: 18) 1lamaba la atención sobre la vaguedad que rodea al término; a su juicio resulta difícil saber exactamente qué significa.

15 Según Bosque (2014: 67) sería básicamente la interpretación de Levin y Rappaport.

16 Como ha señalado Bosque (2014: 41) a propósito de los significados de los participios. 
resultativo a partir de fregar los platos, puesto que no contiene un verbo de cambio, ni a partir de leer un libro ya que, si bien la acción que denota implica un final, ese final no tiene "como consecuencia un determinado resultado" (Bosque, 1990: 181). La condición de que el verbo denote un estado resultado de un cambio explicaría asimismo para algunos investigadores la anomalía de *Una canción está cantada ${ }^{17}$-"es difícil determinar si una canción ve alteradas sus propiedades al ser cantada" (Fernández et al., 2003: 11)- o de El río está cruzado: cruzar un río configura una situación acotada temporalmente, pero de ella no se deriva ningún resultado, no supone que el río se vea afectado "de la misma forma que una puerta al ser abierta o una barra al ser doblada" (Marín, 2004: 28).

Así pues, ni leer la novela, ni cantar la canción o cruzar el río implicarían un estado resultante en este sentido ni, en consecuencia, los predicados se considerarían, según este planteamiento más restrictivo, habilitados para formar construcciones resultativas que atribuyan al sujeto un estado.

No obstante, las referencias a los condicionamientos antes recogidas sugieren que para otros estudiosos no es la denotación del cambio, sino la telicidad del verbo o del predicado -es decir, el hecho de que aluda a un evento delimitado, con "culminación"- el rasgo que se destaca como condicionante de la construcción resultativa y de la configuración de un estado resultante. En opinión de Conti (2004: 24), por ejemplo, se halla limitada, al igual que la pasiva con ser, a lexemas verbales que denotan un cambio de estado o "un evento susceptible de ser interpretado télicamente". Para Jurado, según se reflejaba en algunas citas anteriormente incluidas, la viabilidad de La lección está explicada, La cima está alcanzada o El patio está barrido, que no están formadas por verbos de cambio, se basa en la telicidad de estos predicados: todos tienen un final "más allá del cual no pueden continuar y en el cual dan origen a algunos estados resultantes" (2000: 184), que son, a su juicio, los estados destacados mediante la construcción con estar. También la Academia (2009: 2214-5) hace extensiva la construcción "con participios que designan el estado resultante de una acción o proceso" a los verbos transitivos de "realización o consecución" que "poseen término", entre los que incluye, por ejemplo, ganar la carrera, alcanzar la cima o leer un diario (2009: 1692), que no expresan ni creación, ni destrucción ni modificación de algo; así, señala al respecto que el hecho de leer un libro "no afecta al libro", pero si alguien puede decir de una novela que "ya está leída", es "natural interpretar la novela como objeto afectado", pues lo que resulta relevante "es la existencia o la presencia de un límite como componente natural del proceso" (2009: 1700).

Esta relación entre las nociones de 'cambio', 'telicidad' ('culminación', 'delimitación') y 'estado resultante' no es, desde luego, inusual en los estudios sobre la semántica de las unidades verbales. Para Pustejovsky (1991: 51), por ejemplo, el estado resultante es una propiedad de los eventos télicos; todos, desde su punto de vista, son complejos, con dos subeventos, un proceso y una transición a "some sort of resultant state"; Tenny (1987: 75) enlaza culminación del evento con la afectación del objeto ${ }^{18}$ y el subsiguiente estado resultado, de ahí que, en su opinión, read the novel, climb the mountain, cross the dessert configurarían eventos con un argumento afectado y un estado resultante. En esa misma línea De Miguel (2001, 2004: 189) afirma que verbos o predicados como leer un libro, ver la

17 No obstante, el uso de "una" en lugar de "la" contribuye a la "anomalía" de la construcción

18 La afectación sería, desde su punto de vista, una propiedad aspectual dependiente de que "the direct argument of the verb" delimite el evento (Tenny, 1987: 75). 
película denotan eventos complejos que incorporan actividades o procesos que desembocan en un punto seguido de un "cambio de estado", igual que pintar un cuadro. En definitiva, desde esta perspectiva todos los eventos télicos "involve a TRANSITION from one event to a second, often from an atelic process to a result state" (Levin, 2009: 16). Por tanto, puesto que cruzar el río, leer la novela, cantar la canción denotan eventos télicos, con un argumento de trayectoria (Morimoto, 1998: 45; Marín, 2004: 28) cuya extensión delimita el evento y lo dota de una culminación natural (Bosque, 1990: 181), también darían lugar, desde esta perspectiva, a un estado resultante.

Queda pues patente que de leer la novela, cantar la canción o cruzar el río se ha podido justificar tanto que dan lugar a un estado resultante como todo lo contrario ${ }^{19}$; de alcanzar la cima, fregar los platos o barrer el patio se ha dicho que permiten ${ }^{20}$ la formación de construcciones resultativas que enfocan el estado originado por el predicado, pero también que la rechazan porque los verbos no incluyen un estado resultante en su significado; las construcciones que integran El piso está vendido/comprado, Las solicitudes están revisadas se han catalogado bien como resultativas que atribuyen al sujeto un estado, bien como construcciones que son semejantes en la forma a esas resultativas, pero que solo serían gramaticales con otra interpretación, precisamente porque en ellas "no se asocia ninguna propiedad al sujeto" que resulte del evento y "nos permita caracterizarlo" (Fernández et al., 2002: 391; Vázquez y Fernández, 2003: 13). Es lógico concluir, por tanto, que, aun cuando "estado resultante" se emplee frecuentemente como si fuera un término unívoco y no se considere necesario definir con qué sentido específico se está utilizando, la noción que le subyace no puede ser la misma en todos los casos.

No sería posible tratar ahora con profundidad cuestiones tan largamente discutidas en la investigación lingüística como la afectación, la telicidad, el cambio, que están implicadas en los sentidos de "estado resultante". Pero, de cara a clarificar las lecturas y los condicionamientos de las construcciones catalogadas como resultativas, estimo pertinente destacar en primer lugar que, como indican Levin y Rappaport (2005: 93), un evento télico, con culminación, no implica necesariamente un estado resultante en el sentido más restrictivo anteriormente comentado; según sus términos "an event can have a culmination without defining an obvious result state", un cambio en las propiedades de una entidad que pueda ser interpretado a partir del significado básico codificado por el verbo; por ejemplo, memorizar el discurso es un predicado télico, tiene "a natural culmination" (Levin y Rappaport, 2005: 93), pero, desde su punto de vista, "it is difficult to characterize accurately what the result state is". El evento de alcanzar la cima, por poner otro ejemplo, sería "verdad", siguiendo a Rappaport (2008: 20) "just in case we went from not being at the summit to being at the summit"; estaríamos hablando, por tanto, de un cambio en la ubicación del sujeto, de un

19 No son desde luego inusuales las diferencias de opinión respecto al contenido léxico-aspectual de los verbos y respecto a la denotación de un "resultado" en particular. Del verbo vigilar, frecuentemente citado en los trabajos sobre las construcciones de participio con estar, se ha dicho, por ejemplo, que es un verbo de actividad, que no forma predicados que den lugar a un estado resultante (véase Jurado, 2000: 187), pero también se ha dicho que incorpora un estado resultado de un evento de transición previo, que ha alcanzado su final y da lugar a un "estado nuevo" (De Miguel, 2001, 2004). Frente a ambos supuestos, Fábregas y Marín (2012: 13) afirman que las predicaciones del tipo alguien vigila el garaje no configuran ni una actividad ni una transición; antes bien, las consideran predicaciones estativas que denotan una relación entre dos entidades.

20 Por ejemplo, el concepto de estado resultado asociado a los verbos de cambio, puede predecir "that verbal PPrts denoting no result will be excluded" de las construcciones con estar (Bosque, 2014: 67). 
sujeto "being at the summit”, pero ¿cuáles son las propiedades de la cima que cambian al realizarse el evento? Si leer el periódico, a diferencia de escribir la novela, no indica, como afirma Bosque (1990: 181), un determinado resultado, no se entiende muy bien que sea natural interpretar que en La novela ya está leída el sujeto representa al objeto afectado, si ha de entenderse como tal una entidad que ha experimentado un cambio en sus propiedades como resultado de la lectura ${ }^{21}$; afirmar que el cambio sufrido por la novela "is that of "becoming read"" no puede entenderse como una justificación de que las propiedades de la novela se hayan visto alteradas; de conformidad con Rappaport (2008: 34), la misma afirmación se podría aplicar al objeto de cualquier verbo de actividad: “ if I tickle my daughter, we can say that my daughter has 'become tickled"" aunque tickle no se clasificaría "as a [+change] verb". En realidad, mediante justificaciones de este tipo el concepto acabaría siendo tan vago que, como indicaba Marín (2004: 18), casi “cualquier cosa" podría ser concebida "como resultado de un cambio".

En segundo lugar, de aceptar que también La novela ya está leida, La cima ya está alcanzada designan un "estado resultante" porque perfilan el "estado" que tiene lugar cuando las acciones que configuran leer la novela, alcanzar la cima finalizan -llegan a su término, a su culminación natural- habrá de admitirse asimismo que el término "estado resultante" no puede tener en estos casos el mismo sentido cualitativo, intensional, alusivo a propiedades, que se asocia a los enunciados formados por verbos de cambio ${ }^{22}$. Antes bien, el concepto que puede inferirse se habría de definir, al igual que el "resultant state" que Parsons (1990: 234) delimita como interpretación del "perfecto"23 (apud Kratzer, 2000: 386), en un eje meramente temporal, como "the state of the base eventuality having ocurred" (Nishiyama y Koening, 2010: 618); en términos de Parsons, se trataría simplemente de "the state of e's having culminated", que sigue indefectiblemente a "every event e that culminates" 24 (apud Kratzer, 2000: 386, 387); el "estado resultante" en este sentido no denotaría, pues, propiedades atribuibles a una entidad; solo vendría a designar la situación, el estado de cosas, que sigue a la conclusión del evento. Utilizando un ejemplo de Maienborn (2009: 37), si se considera que en The manuscript is submitted, let's turn to the project proposal now la "pasiva adjetiva" expresa un estado resultante, el término habría de entenderse, en ese sentido temporal -o temporal-aspectual ${ }^{25}$, no cualitativo, que se ha destacado: no incluiría al manuscrito en "the class of submitted papers, rather tan being, e.g., accepted or published of rejected"26 (Maienborn, 2009: 37); referiría simplemente a "the post state of a submitting

21 Según Rappaport (2008: 25), "read not entail a change in the denotee of its direct object, but rather in that of its subject. If you want to know if a road sign was read by someone, you don't check anything about the road sing, but you do check something about the reader". Señala asimismo que "verbs like read even on their telic reading, are not associated with a result state (...) verbs such as read and other information ingestion verbs, such as study and peruse, do not pass any of the test which have been offered to probe the existence of a state predicate" (2008: 33). Bosque (2014: 61), por su parte, afirma que "reading something is not 'causing it to be read' but being involved in a process of following something along a course".

22 De ahí quizá el recurso a expresiones del tipo "some sort of resultant state" (Pustejovsky, 1991: 51), "cierto estado resultante" (RAE, 2009: 1820), cuando se analizan estos casos.

23 Un sentido “conditioned by an implicit HAVE” según Bosque (2014: 68).

24 Con palabras de Nishiyama y Koening (2010: 617-618) el estado resultante se caracterizaría en este caso "by his following the base eventuality" a lo que añaden que "introducing such states unduly populates de space of states".

25 Véase Bosque, 2014.

26 Esa lectura cualitativa sería la que se desprendería de The manuscript is submitted, but not accepted/published.... (Maienborn, 2009: 37). 
event" (ibid.), a la situación subsiguiente a la conclusión del evento en la que la tarea de enviar el artículo ya se ha llevado a cabo, en contraste con el espacio temporal previo en el que la acción no se había realizado ${ }^{27}$.

\section{A propósito de la interpretación de las construcciones resultativas: el sentido atri- butivo y el sentido de fase}

De lo tratado anteriormente se puede colegir que, si bien construcciones del tipo La novela ya está leida se han mezclado frecuentemente con las del tipo La novela está bien escrita o La ciudad está destruida, como si formaran una sola categoría "resultativa", tienen en realidad interpretaciones distintas, paralelas a los dos sentidos de "estado resultante" que se han diferenciado.

Considérese, por ejemplo, el sentido de ya está leída/o en los siguientes enunciados tomados de Internet ${ }^{28}$ :

1. Sus novelas anteriores me encantaron y tenía muchas ganas de leer esta por lo que en cuanto cayó en mis manos me puse con ella. Ya está leída y me ha encantado aunque disfruté más con las anteriores.

2. [El libro] me lo envía Punto de lectura. ¡Mil gracias! Ya está leído; lo terminé anoche.

No predican de la novela o de el libro una propiedad que hayan adquirido como resultado de la acción de leer y que los diferencie en un plano cualitativo de una novela o de un libro "no leídos"; no tienen, pues, la interpretación cualitativa, de caracterización, que sí tendría La novela está bien escrita. La lectura que configura la construcción se relaciona, por el contrario, con ese sentido más temporal, vinculado al "aspecto perfecto" que también se ha asociado a "estado resultante": perfilaría el estado de cosas que sigue de manera inmediata a la culminación del evento -la lectura de la novela o del libro-, a su terminación, en contraste con el estadio temporal previo en el que no se daba esa situación ${ }^{29}$.

Además, frente al carácter estativo que se considera propio de los enunciados resultativos, no parece que el evento ${ }^{30}$, la actividad previa denotada por el verbo, esté "totalmente ausente" en la interpretación de este tipo de enunciados, según puede deducirse del contraste entre, por ejemplo, El armario está vacio y El armario ya está vaciado.

27 Para Kratzer (2000: 395), por poner otro ejemplo, si el enunciado The building is evacuated fuera emitido por un policía que informa a su supervisor de que la acción de evacuar el edificio ya se ha llevado a cabo, tendría una interpretación temporal, no atributiva.

28 Los enunciados que se utilizan como ejemplos proceden de textos obtenidos a través de Internet. Al final se incluye un apéndice con las páginas de donde se han extraído.

29 Como de "evento finalizado" catalogan Vázquez y Fernández (2003: 160) las construcciones del tipo El piso ya está vendido porque no denotan una propiedad que haya adquirido el sujeto sino una "propiedad del evento", en concreto que este "ha finalizado" y "como resultado se enuncia la oración del ejemplo". Escandell y Leonetti (2002: 169) describen como "the end of the process reading", diferente de la meramente estativa la interpretación de las construcciones absolutas. Se ha de subrayar, sin embargo, que no es tanto la finalización en sí lo que focaliza la construcción como la situación, el estadio, inmediatamente posterior a la finalización.

30 Bosque (2014: 46) indica al respecto que llenado, secado, son participios eventivos, a diferencia de lleno, seco que serían "R-PPrts", es decir, participios resultativos. Véase también Alexiadou (2005: 18). 
Según se dijo anteriormente, está limpio, está seco, está vacio, que incluyen participios truncos o adjetivos perfectivos, se han considerado construcciones resultativas -alternativas a las que podrían formarse con los correspondientes participios regulares- porque, al igual que las formadas con participios como está cerrado, está destruido, atribuyen un estado interpretable "como resultado de una acción o proceso" (Bosque, 1990: 178); no obstante también se ha señalado que, cuando existe el participio regular junto al participio trunco, no vehiculan el mismo tipo de significado ${ }^{31}$. Con el participio trunco el estado denotado puede concebirse sin pensar necesariamente en los procesos ${ }^{32}$ que lo llevan a cabo porque la naturaleza eventiva del verbo "habría desaparecido para dejar solo el significado correspondiente al estado final” (Bosque, 1999: 279). Así, como indica Bosque (1990: 186), de una habitación puede decirse que "está vacía" sin que previamente se haya vaciado. Con el participio regular está vaciada, en cambio, "es preciso tener en cuenta el proceso" por el que se obtiene el estado resultado ${ }^{33}$ (Bosque, 1999; 285; RAE 2009: 2093); por consiguiente, las construcciones de participio con estar que se incluyen más abajo no son equivalentes a las construcciones atributivas, “de caracterización”, La pista está seca, El buzón está vacío, El sendero está limpio ${ }^{34}$, puesto que en su interpretación sí estarían presentes las acciones a las que aluden los participios, sí obligan a interpretar que alguien ha llevado a cabo esas acciones de secar, limpiar, vaciar, que ya han terminado:

3. La pista ya está secada [...] en 15 min. empieza esto.

4. El sendero esta limpiado recientemente, porque yo lo recordaba muy dejado y difícil de seguir.

5. No me había dado cuenta de que tenía el buzón 1leno, pero ya está vaciado.

Habida cuenta de la eventividad y de la denotación del estado de cosas inmediatamente posterior a la finalización, se podría catalogar esta clase de construcción como una "perífrasis de fase", es decir, como una de las perífrasis que focalizan una de las "etapas ordenadas cronológicamente de un evento" 35 , una característica que, según recoge la gramática de la Academia $^{36}$ (2009: 2215), algunos investigadores atribuyen a las construcciones de participio con estar, pero de dudosa aplicación a las "otras" construcciones resultativas, a las "de caracterización".

Ese sentido "de fase" relacionado con el aspecto perfecto explicaría las "mejoras" que, según los estudios que se han ido citando, experimentan determinadas predicaciones si incluyen $y a$, así como la frecuente presencia de este adverbio en los enunciados con que se ilustra la combinación de los participios con estar. Al fin y al cabo, a diferencia de bien, ya es un adverbio "de fase", "aspectual”37, que según García Fernández (1999: 3155; 1995:

31 Véase asimismo Embick (2009: 12-13; 2004: 357, 361).

32 Aun cuando los procesos puedan entenderse como implicados.

33 Asimismo, según Hengelved (1986: 413), la diferencia entre "está entristecido" y "está triste” es que la primera presenta el estado como resultado de un proceso y la segunda no.

34 Considérese que La pista está seca, pero nadie la ha secado no implica contradicción, pero no se puede decir lo mismo de La pistada está secada, pero nadie la ha secado.

35 Así describe la gramática de la Academia "las fases de una situación” (RAE, 2008: 2331).

36 La Academia no se pronuncia claramente al respecto, pero parece sugerir alguna objeción a que se pueda hacer extensiva esa condición de "perífrasis fasal" a las construcciones de participio con estar.

37 En palabras de Bosque (1990: 194), ya es un adverbio aspectual que denota "el estado inmediatamente posterior al obtenido cuando se ha llegado al resultado del proceso significado por el predicado". 
366), discrimina la lectura del aspecto perfecto ${ }^{38}$ porque permite referir a un momento posterior a la realización del evento, un momento "en el que se considera el estado de cosas" que es su consecuencia o resultado.

Ahora bien, a la presencia del evento y a ese sentido "más temporal" de estas construcciones, habría que añadir otro rasgo al que también apunta el recurso a ya. Este adverbio de fase, aspectual, no solo incide en la situación posterior a la terminación del evento; se le atribuye, además, la confirmación de "expected situations" (Bosque, 2014: 69), o la "inducción de una expectativa" (RAE, 2009: 2336; Girón, 1991: 13): que la situación descrita por el predicado no se daba en una fase anterior, pero que se esperaba que se diera; por tanto, las "mejoras" de las construcciones con $y a$, su inclusión habitual en enunciados con este sentido de fase, temporal, vendrían a poner de relieve, de conformidad con Delbecque (2006), que hay algo más que esa incidencia en la fase posterior a la terminación ${ }^{39}$ : la implicación de que el evento denotado forma parte de un guion, de cierto tipo de programación más amplia, compuesta de fases que se conciben como tareas que han de ser superadas y cuya secuenciación puede venir dada "por el orden de las cosas, las costumbres, las convenciones culturalmente arraigadas" (Delbecque, 2006: 47).

En el siguiente enunciado, por ejemplo, la combinación de la construcción de participio con el adverbio ya lleva a interpretar que la consecución del primer objetivo se inserta en una serie de objetivos escalonados que han de cumplirse para la adecuada andadura del máster:

6. ¿Qué objetivos quieren alcanzar en este primer año del máster? V T: El primer objetivo ya está alcanzado: conseguir la acreditación nacional oficial del título y despertar el interés de los alumnos.

En este otro el logro de "ese peldaño" ha de entenderse asimismo como el cumplimiento de una de las fases que han de superarse en el marco de "la campaña":

7. Finalmente, señaló que él y sus pupilos irán paso a paso en la campaña y por lo pronto este peldaño ya está escalado.

En el fragmento que se incluye más abajo la construcción de participio con ya destaca la situación posterior al término de cada una de tres fases ordenadas que forman parte del proceso de ingestión:

8. [Ese postre] lo hice el año pasado así que ya está comido, digerido y metabolizado.

38 Según García Fernández (1995: 367), en A las tres Juan ya había escrito la carta la presencia de ya conlleva que el complemento temporal no incide en el evento sino en la situación posterior, como considera propio del aspecto perfecto, de ahí que, según sus términos, sea parafraseable por la "perífrasis resultativa pasiva" "estar+participio" que perfila el valor "perfecto": A las tres la carta ya estaba escrita (García Fernández, 1995: 367). Es también de destacar que casi todos los ejemplos con que García Fernández $(1999,1995)$ ilustra la noción de 'aspecto perfecto' incluyen $y a$.

39 Así, desde el punto de vista de Delbecque, Ya he comprado los ingredientes no solo indica que la acción de comprar los ingredientes ya ha finalizado, sino también que forma parte de un plan, como puede ser la ejecución de una receta; igualmente, en Ya han asentado la cerradura la inclusión de ya posibilita "la impresión de estar a la altura de los procedimientos habituales" (2006: 63), cosa que no ocurre en Han asentado la cerradura pese a su perfectividad. 
En el siguiente, por último, se hace patente que los participios combinados con estar no solo aluden a una fase subsiguiente a la finalización de las acciones designadas por los verbos; también llevan a interpretar que esas acciones formaban parte de un plan, de una serie de tareas escalonadas que el que emite el enunciado se había impuesto realizar:

9. Ya está examinado, valorado, criticado y sufrido hasta límites de insoportable minuciosidad.

En suma, la combinación del participio con estar configuraría en estos casos un sentido equiparable al que Maienborn (2009) y Gehrke (2012) por ejemplo, tomando como base a Kratzer (2000), identifican como lectura "post state"40 con el matiz "the job is done" para las construcciones equivalentes en alemán.

Queda fuera de los objetivos de este trabajo tratar de forma pormenorizada las peculiaridades de las construcciones del tipo La cima ya está alcanzada o La novela ya está leída. Pero puesto que sí se ha planteado la relación entre los varios sentidos que pueden subyacer al término "estado resultante", la mezcla de construcciones con sentidos distintos como si formaran una sola clase y las diferencias de opinión sobre la gramaticalidad o aceptabilidad de determinadas construcciones, debe subrayarse asimismo que esas dos "interpretaciones" que se han diferenciado no tienen que estar sometidas a los mismos condicionantes ni tienen por qué implicar los mismos procesos sintácticos ${ }^{41}$.

De entrada, parece claro que las construcciones con ese sentido temporal, de fase, no tienen por qué estar restringidas a verbos que incluyan un estado resultante en su estructura léxica. Así, La canción está cantada, El río está cruzado serán anómalas si se proyecta sobre ellas una interpretación cualitativa, atributiva o de caracterización; pero no lo serían como construcciones de "fase posterior", vinculadas a ese sentido de "estado resultante" no atributivo, más temporal, como ponen de manifiesto los siguientes enunciados tomados de Internet:

10. Ya está cruzado el enésimo puente, el último de la carrera; [ahora] giro a la izquierda y a tirar hacia el Paseo Echegaray.

11. Hay que entender que la canción ya está cantada, grabada y lo que sea.

Igualmente, de conformidad con Bosque (1999: 288) El libro está sacado de la estantería puede ser anómala con una lectura atributiva, de propiedad, porque el verbo sacar no alude a una actividad "cuyo resultado se pueda medir o evaluar", pero no parece que haya ninguna anomalía en este otro enunciado con el verbo sacar del que se deduce esa interpretación de fase subrayada por ya:

40 Se trata de la lectura que Kratzer (2000) identifica específicamente como "resultant state" para diferenciarla de la interpretación "target state".

41 Según Kratzer (2000: 395) estás construcciones en las que el participio tiene un sentido temporal "are more widely available tan target state participles". Los procesos sintácticos que intervienen en la formación de estas construcciones plantean también cuestiones controvertidas. Así, según señala Bosque, resulta especialmente problemático "what specific layers are involved" en las lecturas de los participios o de las construcciones resultativas, si están "related to aspect, voice, the event itself of its result". Para Kratzer (2000: 395), por ejemplo, el participio con esa lectura temporal eventiva "involves an aspectual operator". Desde el punto de vista de Maienborn (2009: 35) las dos lecturas se derivan "from a semantically underspecified representation that requires the pragmatic machinery to infer a suitable contextual instantiation". 
12. No me esperaba que fueran tan malas [...] de todas maneras, ya están sacadas de la bolsa, conque no las puedo cambiar.

Es más, en la medida en que el guion, el marco en el que se sitúan las fases, pone en juego "una base de conocimientos enciclopédicos o experiencias compartidas por el enunciador y el receptor" (Wilk- Racieska, 2012: 38) y viene dado por factores no estrictamente gramaticales, es de esperar que tampoco las condiciones para esta clase de construcciones se ciñan a cuestiones aspectuales o de índole gramatical. Las posibilidades de formación se abren incluso a los verbos de actividad (Kratzer, 2000: 388, Embick, 2004: 361) siempre que se den "certain contextual conditions" que permitan proyectar esa base programática que "defines the fulfillment of the activity as a contextually salient target that has to be achieved" (Gese, Stolterfoth y Maienborn, 2009: 136). Así, por ejemplo, los siguientes enunciados, que tienen esa interpretación "post state"+"job is done"42, están formados por verbos normalmente señalados, por su clase léxico-aspectual ${ }^{43}$, como inhabilitados para formar construcciones resultativas con estar:

13. El chucho ya está paseado y aseado y la menda es requerida por los bancos, a ver si hoy por fin me ponen la alfombra roja como a "la Pé".

14. - Mándales un beso y un abrazote grande de parte de la peña del pedal.

- Gracias José. Ya están besadas y abrazadas todas de tu parte.

Sin embargo, las construcciones de sentido atributivo, como El vaso está roto, La puerta está abierta o La ciudad está destruida ni requieren o implican ${ }^{44}$ ya ni precisan o suponen un "programa" en el que se inserte el evento significado por el verbo base como tarea que ha de ser realizada. Así cuando la gramática académica (2009: 2215) afirma que la construcción de participio con estar -sin más especificaciones- se ve favorecida si el hablante asocia los procesos "con tareas que han de ser superadas" como La casa (ya) ya está vendida y la deuda está pagada, parece estar refiriéndose a las construcciones con sentido de fase, pero habría que matizar que tal requisito no parece hacerse extensivo a "todas" las construcciones resultativas formadas con un participio y el verbo estar.

\section{La clase léxico aspectual y los complementos relacionados con la actividad en las construcciones resultativas de carácter atributivo}

La "anomalía" que se percibe en El río está cruzado, La canción está cantada o El libro está sacado de la estantería si se proyecta en ellas una lectura atributiva pone de manifiesto que ni la telicidad está necesariamente asociada a un estado resultante en el sentido más restrictivo ni garantiza por sí sola la viabilidad de una construcción resultativa con un sentido cualitativo.

42 Son enunciados semejantes a, por ejemplo, Anna has done her neighborly duties: the mailbox is emptied, the flowers are watered and the cat is petted, que Maienborn (2009: 36) utiliza para ilustrar la lectura "the job is done". 43 Anteriormente ya se hizo referencia a besar. En cuanto a pasear, expresa una acción no delimitada, una "actividad".

44 De conformidad con la Academia (2009: 1820-1821) hay construcciones con lectura perfectiva en las que se sobreentiende ya aunque no esté expresado. Bosque (2014: 70) afirma al respecto que "the adverb ya may be omitted if we know, from extralinguistic evidence, that a certain task is expected after others", a lo que añade: "this entailment, clearly triggered by the phasal adverb, is also associated to resultative perfects inside the (so-called) "extended now"'. 
Por el contrario, puesto que los verbos bieventivos, de cambio, como abrir, cerrar, sí incorporan un estado resultante en esa acepción más restrictiva, sí codifican un cambio en las propiedades del argumento afectado, parece claro que han de posibilitar una construcción resultativa en la que el participio asigna al sujeto una propiedad especificada por el verbo y que, por tanto, puede ser interpretada sin necesidad de otros elementos y sin requerir "esfuerzo pragmático" (Maienborn, 2009: 45).

Es evidente asimismo que enunciados como La casa está construida por los albañiles, Este cuadro está pintado por el niño (Conti, 2004: 40), El Quijote está escrito por Cervantes (Bosque, 1999: 293), que incluyen complementos agentivos con la preposición por $^{45}$, resultan en mayor o menor medida anómalos o extraños, según se ha subrayado para justificar el rechazo de las construcciones resultativas a las complementaciones referidas a la acción y no a su resultado.

Sin embargo, como han ido poniendo de manifiesto los estudios sobre este tipo de construcciones en español y en otras lenguas, no se puede concluir que las combinaciones de sentido atributivo estén limitadas a los verbos que lexicalizan un estado resultado ${ }^{46}$ ni que la inclusión de complementos relacionados con el "agente" convierta en anómalos este tipo de enunciados, sin que ello obste para que la combinación "estar+participio" sitúe en primer plano no el proceso, sino su resultado.

Por lo que respecta a la clase léxico-aspectual del verbo, los datos que proporcionan enunciados obtenidos de Internet ponen claramente de manifiesto que también con verbos que no son de cambio ni incorporan un estado resultado léxicamente especificado se forman construcciones con esa lectura "de caracterización", de contenido atributivo, consistente en adscribir al sujeto "a complex property which has to be derived from the verbal base of the participle" (Gese, 2011: 260).

Por ejemplo, más arriba se dijo que memorizar el discurso no lleva aparejado un estado resultante, pero es evidente que en el siguiente enunciado se atribuyen "al discurso", mediante la construcción de participio, ciertos rasgos que, tal como se infiere de las especificaciones contextuales, contrastan en una dimensión cualitativa con, por ejemplo, los que pueda tener un discurso espontáneo:

15. Cuando un discurso está memorizado, pierde calor y fuerza: y suena más a una recitación que a algo que sale desde dentro.

Es asimismo evidente, sin embargo, que esos rasgos que lo pueden oponer al discurso espontáneo no están codificados por memorizar ni pueden interpretarse solo a partir de su significado "retener en la memoria algo".

Diversos estudios han constatado que, en realidad, se puede obtener esta lectura atributiva con otras clases de verbos; que, aunque dar lugar a un estado resultante no forme parte de su significado básico, de alguna manera permiten configurar una propiedad atribuible al sujeto. Como señalan Bosque (1999: 288) o la Academia (RAE, 2009: 2216) no es

45 Igual que Der Brief ist ¿?? von Gabi / von einem Experten geschrieben (Gese, 2011: 260) o *Der Wein ist vom kellner eingeschecnkt=the wine is by-the waiter poured (Rapp, 2001: 396).

46 Como señala Bosque (2014: 67), la interpretación restrictiva de "estado resultado" que adopta Marín (2000; 2004), por ejemplo, llevaría a formular predicciones incorrectas sobre la agramaticalidad de combinaciones de estar con participios de verbos que no incorporan un estado resultante de un cambio. 
sencillo determinar cómo se obtiene esa interpretación con esos otros grupos semánticos de verbos, pero sí parece claro que no depende de la clase léxico-aspectual o del significado lexicalizado.

Por lo que atañe a la insuficiencia de la clase aspectual y de ese significado mínimo lexicalizado al que algunos han constreñido los aspectos relevantes para el análisis lingüístico, ha de subrayarse que uno de los factores que más comúnmente se ha destacado cuando se trata de explicar la posibilidad de formar construcciones resultativas con verbos que no conllevan un estado resultante es el "efecto" causado" en el objeto (RAE, 2009: 2216) -en particular, su "visibilidad" o "perceptibilidad" 47 , aunque ese efecto no esté codificado, no forme parte de su significado básico. Así, por ejemplo, según Hengelved (1986: 412), la anomalía de *La chica está besada se debería a que besada no denota un estado visible y ello limita su combinación con estar. Y, en efecto, participan de esta construcción verbos que, si bien no incluyen un cambio de estado en su significado básico, aluden a acciones que tienen efectos "perceptibles" 48 típicamente asociados. Por ejemplo, los verbos barrer y fregar son, según se dijo anteriormente, verbos de actividad ${ }^{49}$, que incorporan la manera de actuar el sujeto, no el resultado, pero sí pueden asociarse a efectos que se producen normalmente en el objeto afectado y que pueden inferirse de otros rasgos más específicos de su significado ${ }^{50}$ : arrastrar basura con una escoba para limpiar, limpiar una cosa con agua...

Así, los siguientes enunciados con el verbo fregar, que ni incorporan ni implican $y a^{51}$, son gramaticales y atribuyen al sujeto un estado convencionalmente asociado a la acción de fregar como pueden ser "estar mojado" (16) o "estar resbaladizo" (17), por el hecho de estar mojado:

16. No podía pisar en la cocina porque el suelo estaba fregado.

17. El pasado 29 de Febrero iba caminando por la planta baja de El Corte Inglés de la Calle Preciados (Madrid) y tuve una caída un tanto aparatosa por culpa de que el suelo estaba fregado y sin indicación.

Está barrida en este otro enunciado tiene el sentido de "está limpia" puesto que el hecho de que el objeto "barrido" quede limpio es un resultado deseable, y perceptible, de la acción de barrer:

18. De modo que regresa y encuentra que su antigua casa está barrida y en orden.

47 Jurado Salinas (2000: 185) afirma que "describen estados visualmente perceptibles"; Fernández Ramírez (1986: 414) hace hincapié en un "resultado que imprime en el objeto un sello o marca visible".

48 Según Levin y Rappaport (2005: 233), "when verbs with manner roots are found in a complex event structure, the type of result must be one that can be naturally obtained given the type of manner".

49 Siguiendo a Levin y Rappaport (véase, por ejemplo, Levin y Rappaport, 1991; Levin y Rappaport, 2013), barrer y fregar serían verbos de actividad que describen un proceso que puede llevarse a cabo indefinidamente y que no codifican alcanzar ningún resultado.

50 Cito a continuación las definiciones que da el DUE (Moliner, M., Diccionario de uso del español, Madrid, Gredos, 1971) de barrer y de fregar:

Barrer: Arrastrar con una escoba o utensilio que haga el mismo efecto basura, desperdicios, etc., para limpiar de ellos el suelo.

Fregar: Limpiar una cosa como los cacharros sucios de comida, el suelo, las puertas... restregándolos con un estropajo, una bayeta, etc., con agua y alguna sustancia adecuada.

51 Es decir, no tiene la interpretación de fase, temporal, alusiva a la realización de una tarea programada. 
Asimismo, mordisquear, por poner otro ejemplo, no es télico ni codifica un cambio en su objeto; es un verbo de actividad que refiere a una manera de actuar del sujeto. Y, sin embargo, no resultan anómalos los siguientes enunciados en los que se atribuye al sujeto un estado que puede entenderse como un efecto visible típico de la acción de mordisquear ${ }^{52}$ -que le falten pequeños trozos o tenga marcas visibles de dientes- aun cuando ese efecto no forme parte de su significado básico:

19. El $40 \%$ restante [de los cuerpos] está mordisqueado por depredadores y carroñeros como prueban las innumerables marcas de colmillos halladas sobre los huesos humanos.

20. Ésta fotografía pretende simbolizar un síntoma de ansiedad. Podemos intuir que el lápiz está mordisqueado por efectos del nerviosismo.

No obstante, como señala la Academia (RAE, 2009: 2216) los efectos pueden ser "inmateriales", no aparecen "gravitando sobre la sustancia como una marca recognoscible" (Fernández Ramírez, 1986: 414); de conformidad con Bosque (2014: 62), la interpretación de esos estados resultantes no codificados por el verbo "might involve more subtle notions" y frecuentemente implican un componente evaluativo, valorativo ${ }^{53}$, que, como se sugirió anteriormente, ni depende solo del verbo -aun tomando en consideración esos otros rasgos más "enciclopédicos"- ni queda constreñido por factores gramaticales.

Por un lado, según plantea Kratzer (2000: 394), es posible que ese componente valorativo no esté proporcionado por el verbo ${ }^{54}$ "but by other material within the VP, a manner adverb, for example". Así ocurre, por ejemplo, en el siguiente enunciado, en el que lo relevante no es el estado subsiguiente al evento de construir sino el componente valorativo aportado por el adverbio cuidadosamente y, de modo más indirecto, por a mano:

21. El sello independiente de joyas Nylon Sky nació del amor por la forma geométrica y los cortes a láser. Habiendo comenzado la etiqueta en Londres, está actualmente radicada en España, donde todo está cuidadosamente construido a mano en su estudio de Barcelona.

También las complementaciones con para pueden proporcionar los datos para inferir la calidad del objeto y configurar ese componente evaluativo, como muestra, por ejemplo, el enunciado que se incluye a continuación:

22. Nuestras bombas están construidas para operar en las condiciones más difíciles del yacimiento petrolífero.

Entre ese "material" que permite moldear el sentido cualitativo asociado a la evaluación es preciso incluir las complementaciones de carácter agentivo introducidas con por, mucho más habituales ${ }^{55}$ de lo que sugiere "the traditional view" sobre estas construcciones que

52 Mordisquear: Morder algo repetidamente y con poca fuerza (DUE).

53 Bosque (1999: 288) plantea que los resultados de la acción se han de poder medir o evaluar. Jurado (2000: 185) habla de un "marco de referencia individualizado" que implica la valoración de un hablante que percibe un estado de cosas y lo compara con un estándar.

54 A juicio de Kratzer (2000: 392), la gramaticalidad de The hair was still combed sloppily "shows that stativization operation that created the target state participle (...) must have affected a phrase, rather than a mere lexical item. Véase también Maienborn (2009: 40).

55 Según Rapp (2001: 396), “von-phrases which seem to refer to the verb's subject argument are often posible 
se mencionó al principio, sin que su presencia suponga en realidad la "instanciación” del evento denotado por el verbo en la interpretación del enunciado.

Así, por ejemplo, citar no sería, según Gehrke (2012: 188), un buen candidato para una construcción resultativa porque no da lugar a una estructura eventiva con un componente estativo. Sin embargo, El texto está citado por Chomsky no solo es una construcción estativa, de caracterización, aceptable, sino que nos dice algo sobre la calidad del texto que lo hace recomendable en la comunidad académica; le atribuye, por tanto, una cualidad que no depende del significado de citar; viene dada por el complemento que permitiría establecer una oposición cualitativa entre "estar citado por Chomsky" y, pongamos por caso, "estar solo citado por un recientemente graduado".

Bruhn de Garavito y Valenzuela (2008: 329) consideran que *La cena ya está preparada por un cocinero profesional resultaría anómala debido a la complementación agentiva, pero, en realidad, la anomalía no parece provenir del complemento "por un cocinero profesional" sino, en todo caso, de $y a$, que, como se dijo anteriormente, se vincula a otro tipo de lectura, más "temporal". De hecho, no se pueden considerar anómalos los siguientes enunciados, formados igualmente con el verbo preparar:

23. La comida está preparada por verdaderos expertos y se nota la calidad en los productos.

24. He estado yendo a este restaurante desde que abrió sus puertas, y me encanta la comida. Está preparada por chefs tailandeses y siempre sabe delicioso.

25. La comida está preparada por nuestro chef Andrew Kelso y su equipo, proporcionando un menú variado, mezcla de la cocina tradicional y la moderna, usando los mejores productos locales.

26. Si te gusta la comida árabe podéis ir los viernes a la noche al Colegio armenio MARIE MANOUKIAN (Armenia al 1300, Palermo), te atienden los alumnos de quinto año y la comida está preparada por las madres, lo que te garantiza su "caserismo".

Pero no focalizan la atribución al sujeto del estado configurado por preparada como opuesto a "no preparada"; atribuyen a la comida una propiedad con un componente evaluativo - la calidad, la excelencia, en 23-25, la condición, asimismo valorativa, con un componente afectivo "maternal", de "casera" en 26- que viene dado por las complementaciones "agentivas" -por verdaderos expertos, por chefs tailandeses, nuestro chef Andrew Kelso, por las madres- y no solo por preparar.

Algo similar se puede decir de los siguientes enunciados en los que las construcciones están formadas a partir del verbo cocinar; no establecen un contraste entre el "estado" resultante de cocinar y el previo que corresponde al evento no realizado ${ }^{56}$. La propiedad que atribuyen al sujeto tiene que ver no ya con el hecho de "estar cocinado" - es decir, no se oponen "platos sin cocinar" a "platos cocinados"-, sino con la "calidad" que se infiere del complemento introducido con por:

with the adjectival passive (...) The adjectival passive allows for von-phrases that are characteristic of the result state, but not for those that just describe de event proper"; véase asimismo Gehrke y Sánchez Marco (2014). 56 De conformidad con Gehrke (2012: 204) El pollo está cocinado puede tener dos lecturas, igual que The meat is cooked: una lectura "post" -El pollo (ya) está cocinado. Podemos comerlo- y una lectura "cualitativa" o "de caracterización”: El pollo está cocinado, no precocinado, por ejemplo. 
27. Si lo que tienen que ingerir no está cocinado por un chef desconocido, no tiene un nombre larguísimo y complicado y no presenta un aspecto psicodélico y nunca visto, ni se dignan a metérselo en la boca.

28. Carnes y pescados a la brasa, cocido madrileño, gachas o migas. Cualquiera de estos platos te va a parecer que está cocinado por un ser superior, ¡sólo te faltará pedirle un autógrafo!

29. Una tortilla de patatas no es una lata de caviar y sin embargo, si está cocinada por un maestro como Mundi, no solo se le puede igualar... es que la sobrepasa de largo.

30. Empezando por el trato, que es de lo más amable y cercano posible, hasta los platos, que se nota que están cocinados por alguien con muchos años en la cocina y siempre de forma casera.

Igualmente en los siguientes enunciados se atribuye a los "artículos" y al "material" una calidad que no está especificada en el significado léxico de "revisar" ni puede depender solo de su interpretación. Es nuevamente la complementación el elemento que permite establecer un contraste cualitativo con otros artículos o materiales no sujetos a ese tipo de revisión:

31. Cada serie de libros se ha elaborado por encargo especial, y cada artículo de las publicaciones está revisado por colegas profesionales para asegurar la presentación de investigaciones de alta calidad por su aplicación práctica y relevancia en el terreno.

32. Todo el material que se introduce en NiceTales está revisado por un equipo de educadores y especialistas en edición que leen y consideran los cuentos para establecer unos estándares de calidad lo más altos posibles.

Tampoco en estos otros se atribuye al sujeto una cualidad codificada únicamente por el participio; son nuevamente los complementos los que nos dicen algo sobre la "calidad" del sujeto:

33. El piso piloto está amueblado por Nusco Mobiliario.

34. Este apartamento de Madrid está decorado por uno de los diseñadores de interiores más importantes de nuestro país: Tomás Alía.

La relevancia de esas complementaciones referidas al agente queda claramente de manifiesto en las construcciones con verbos de creación, como construir, pintar, muy utilizados para ilustrar la "resistencia" de las construcciones resultativas a los complementos relacionados con la actividad, pero también muy discutidos por lo que atañe a la gramaticalidad de las construcciones que forman con estar.

Se dijo al principio que los verbos de creación se consideran habilitados, por su estructura léxica, para formar construcciones resultativas de sentido atributivo y se dijo asimismo que en algún estudio se citan como ejemplo de esta clase enunciados con verbos de creación del tipo La casa está construida. Pero no es menos cierto que estas combinaciones se han considerado anómalas -con ese sentido atributivo, no con interpretación de fase que implica $y a$ - debido a la escasa "informatividad" del estado resultante descrito por el verbo. De conformidad con Batiukova (2006: 232) o Marín (2004: 28-29), por ejemplo, Esta casa está construida, Este cuadro está pintado, Esta novela está escrita no serían aceptables porque la información que transmitiríamos sería simplemente que la casa, el cuadro, la novela existen (estado resultante) y que se crearon "in specific ways" (Goldberg y Ackerman, 2001: 803) -construyendo, pintando o escribiendo-, pero el artículo definido ya implica la existencia 
del objeto y la información de que han sido creados mediante un cierto tipo de proceso ${ }^{57}$ estaría asimismo contenida "a nivel subléxico" en casa, cuadro, novela; de ahí que resultaría "informativamente vacío" atribuirles simplemente como "estado" la llegada a la existencia mediante este tipo característico de proceso ${ }^{58}$; como indican Goldberg y Ackerman (2001: 803), "an utterance asserting that a house was built simply states what is already known to competent participants in a conversation"; sin embargo, La casa está bien construida, La novela está escrita con mucha sensibilidad sí atribuirían al sujeto, mediante los complementos, propiedades informativamente relevantes, al igual que sucede con el complemento "agentivo" en El cuadro está pintado por Velázquez. En los siguientes enunciados, la propiedad "cualitativa", la "evaluación" del sujeto, viene dada por las complementaciones "de manera":

35. Está redactada en bonito y todo.

36. Nuestras pólizas están redactadas de forma clara y transparente.

En estos otros la incorporación de complementos agentivos con por no solo no convierten en agramatical la construcción, sino que también son los elementos que confieren ese componente valorativo, evaluativo, que la hace "aceptable" y que, evidentemente, no se desprende solo del estado alusivo a la llegada a la existencia codificado por el verbo de creación:

37. Todas las guitarras a partir del $8 \mathrm{P}$ están construidas por un pequeño grupo de experimentados artesanos.

38. El cartel de la II Fira d'Art está diseñado por Josep Serra del estudio Ménsula.

39. La música está compuesta por el ganador del Premios de la Academia Hans Zimmer ("El Rey León").

En realidad, incluso los estudios que destacan la tendencia de estas construcciones a rechazar las complementaciones agentivas acaban admitiendo la existencia de combinaciones de este tipo perfectamente gramaticales. Bosque (1999: 293), por ejemplo, tras afirmar que los participios adjetivales de los verbos transitivos que denotan acción anterior al resultado observado tienden a rechazar el complemento agente cuando se construyen con estar, advertía de "cierta inestabilidad", "que requiere un estudio más pormenorizado", en el caso de los verbos de creación; a este respecto subrayaba el contraste entre Este cuadro está firmado por Salvador Dalí y el enunciado El Quijote ¿?está escrito por Cervantes, dudosamente aceptable. También Conti (2004: 39-40), una vez establecido que "las construcciones resultativas puntuales" "no admiten la aparición del SP-por referido al actor", señalaba la existencia de "casos esporádicos", como El cuadro está pintado por Velázquez, que requerían una explicación. Pero no parece que esa explicación pueda basarse exclusivamente en factores de índole gramatical.

57 Sería distinto si el método de creación fuera inusual (Goldberg y Ackerman, 2001: 804).

58 Como señala Gehrke (2012: 195), "it is somewhat odd to talk about a letter in a state of being written (8.23a) or a plank being sawn (8.24a), given these are the normal states for letters or planks to be in, i.e. letters are usually written and planks are usually sawn. Under the current account, we can explain the improvement of the examples because adding the modifiers here creates a subkind, such as written with red ink or cut in two pieces, and thus attributing such a property to letters and planks becomes informative again". 
Para dar razón de estos casos "esporádicos" se ha apelado a la relevancia cultural de la entidad $^{59}$ aludida por el sintagma introducido mediante por-como Velázquez o Chomsky- o a su alta "informatividad". Desde el punto de vista de Conti (2004: 40), por ejemplo, la relevancia de Velázquez según "nuestro conocimiento del mundo" -que no es, obviamente, un rasgo gramatical-, justificaría la buena formación de Este cuadro está pintado por Velázquez frente a El cuadro está pintado por el niño, cuyo complemento agentivo, además de no denotar una "entidad relevante", está formado por un sintagma definido de baja informatividad" Sin embargo, desde mi punto de vista también sería aceptable, y tendría un componente valorativo, No pienso quitar este cuadro. Está pintado por mi niño, pese a que la entidad denotada "mi niño" solo sea relevante para el que habla y esté también representada por un SN definido. Razones puramente informativas, y no gramaticales, podrían igualmente justificar la anomalía, señalada por Bosque, de El Quijote está escrito por Cervantes; por tratarse de un dato sobradamente conocido puede resultar redundante desde el punto de vista informativo; pero no hay anomalía en Este libro debe valer una millonada. Los expertos piensan que está escrito por Cervantes, un enunciado en el que la complementación no solo aporta información, sino que dota de ese componente valorativo que hace aceptable la construcción.

Se ha subrayado asimismo la pertinencia de la "visibilidad" del agente en el estado resultante, quizá uno de los factores más repetidos cuando se trata de justificar la presencia de ese tipo de complementaciones, en teoría descartadas de las construcciones resultativas con estar: el hecho de que "el agente sea reconocible en el estado", que sea "visible" de forma relevante, explicaría, a juicio de Hengelved (1986: 416), que tanto El escrito está firmado por el embajador como Este artículo está escrito por una persona indocta sean construcciones aceptables. Gehrke (2012: 190) destaca igualmente que esa complementación ha de aludir a un participante en el evento cuya participación ha de tener algún impacto o ser visible durante el estado subsiguiente; así El dibujo está hecho por un niño "still display an impact" del actor que ha creado el dibujo; se ha de admitir, sin embargo, que al igual que el efecto causado por el verbo, la huella del "actor", la impronta de su participación, puede ser "indirecta", no perceptible físicamente, inmaterial, como sucede cuando lo que aporta es fama o prestigio en un ámbito determinado que repercute en la valoración del objeto afectado; así, el hecho de que Chomsky cite un artículo, pongamos por caso, tiene un impacto en la valoración de ese artículo, pero no se puede hablar en sentido estricto de su huella física, de su "visibilidad". Recuérdese a este respecto que, por ejemplo, La chica está besada se ha catalogado como anómala porque besar no desemboca en un estado "visible"; difícilmente pues el agente podría dejar un "impacto visible" en el estado del argumento objeto de besar. Pero que participe un "agente" al que nuestro conocimiento del mundo otorga relevancia sí puede tener un "impacto" en la valoración del objeto, como ponen de manifiesto los siguientes enunciados formados con el participio de besar y un complemento alusivo al "actor" que aporta un componente evaluativo y posibilita la lectura atributiva, de caracterización:

59 Según Gehrke y Sánchez (1914: 202), "the respective person has to be somewhat 'famous enough"”.

60 Conti (2004: 40) trata de delimitar factores relacionados con la "alta informatividad" del complemento. En ese sentido, además de la "relevancia" de la entidad, apunta a que se trate de un sintagma indefinido (El cuadro está pintado por un niño/*el niño) o que sea un complemento contrastivo (Este cuadro está pintado por mi amigo, no por el tuyo). 
40. Me dijo Ud. que este Rosario está besado por la Santísima Virgen de Garabandal.

41. Consíganlos. Yo ya tengo el mío. Está buenísimo. Además, [los discos] están besados por Justin.

42. Esta medalla está besada por el Papa Pío X o Pío Xl (no recuerdo bien).

Los datos muestran, pues, que no solo son admisibles en las construcciones resultativas complementos de carácter agentivo introducidos mediante por, sino que en muchos enunciados la aceptabilidad viene dada por su inclusión en cuanto que permite inferir un contenido cualitativo que no depende solo del participio, que tampoco se explica por rasgos estrictamente gramaticales y que no existiría sin esa complementación.

Como sucede con tantas otras cuestiones lingüísticas, las peculiaridades de este tipo de complementaciones comparadas con las que se incluyen en las pasivas perifrásticas -las pasivas consideradas "eventivas"- suscitan interrogantes que dan lugar a controversias. Se ha planteado si estos complementos agentivos son diferentes de los que forman parte de las pasivas $^{61}$, si inciden sobre el evento o solo sobre el resultado (Rapp, 2001: 396; Alexiadou, 2005: 18), si están habilitadas "by the causative (or argentive) semantics associated with the underlying verb, rather than voice" (Gehrke y Sánchez Marco, 2014: 190). No obstante, para los objetivos de este trabajo puede ser suficiente señalar que ni estos complementos "agentivos" suponen que el evento denotado por la base verbal no esté desfocalizado, ni hay en realidad razones gramaticales para establecer un vínculo necesario entre la desaparición "total" del agente y el hecho de que la construcción no incida sobre la acción sino sobre su resultado. Sin entrar en otras consideraciones, baste subrayar que, al fin y al cabo, los participios que forman parte de estas combinaciones no se han "adjetivado" ${ }^{2}$, no han perdido su carácter verbal ni, por tanto, tienen por qué haber "olvidado" que los procesos que describen implican que un agente -en sentido amplio- los origine o los lleve a cabo. Así, por ejemplo, en Este candidato incluye en su currículum un artículo citado por Chomsky, Un material revisado por especialistas ofrece más garantías, citado por Chomsky, revisado por especialistas aportan una cualidad del artículo o del material, no focalizan un evento de citar o revisar ${ }^{63}$. Ha de destacarse asimismo que ni la existencia de una complementación agentiva garantiza, según la Academia ${ }^{64}$ (RAE, 2009: 2896), que la construcción en que se incluye tenga una interpretación oracional ni, desde luego, estos complementos "agentivos" serían los únicos que no "instancian" un evento ubicado en el espacio y en el tiempo; así ocurre con los sintagmas "agentivos" de las nominalizaciones o de los adjetivos formados con el sufijo -ble (Alexiadou, 2005: 19; RAE, 2009: 2896; Bosque, 2014: 54).

En definitiva, en Este rosario está besado por la Santísima Virgen de Garabandal, Todo el material que se introduce en NiceTales está revisado por un equipo de educadores y especialistas en edición no están perfilados los eventos de besar o revisar; atribuyen a este

61 Como explican Gehrke y Marco (2014), el estatus de estos complementos en relación con los que se incluyen en las pasivas es una cuestión discutida. Desde su punto de vista, son diferentes; mientras los de las pasivas se relacionan con "event tokens", los de las resultativas modificarían "event kinds" (2014: 190).

62 De conformidad con Bosque (2014: 44), las pasivas resultativas en inglés se consideran adjetivas por muchos autores, pero en español, a su juicio, los participios derivados de verbos transitivos pertenecen a categorías verbales, no adjetivas.

63 Tampoco, como evidencian las construcciones pasivo-reflejas, la eventividad, la implicación de un agente, garantiza que se pueda incluir un complemento agentivo. Todo depende de los aspectos que perfile la construcción. 64 Así lo afirma a propósito de las complementaciones agentivas en las construcciones absolutas. 
rosario, a todo el material una cualidades - grosso modo, propiedades divinas, calidad- no codificadas por el participio, sino deducibles de besado por la Santísima Virgen de Garabandal, revisado por un equipo de educadores y especialistas, que permiten establecer un contraste, en una dimensión cualitativa, con otros rosarios sin las propiedades atribuidas a los besados por la Santísima Virgen y con otro material sin la calidad que cabe deducir de su revisión por parte de especialistas.

Según lo visto, se podría afirmar, por tanto, en primer lugar, que como sugiere Maienborn (2009: 39-41) la lectura atributiva, de caracterización o propiedad, está mucho más extendida de lo que puede predecir la mera consideración de la clase léxico aspectual, puesto que la admiten verbos, como besar, en teoría descartados para formar una construcción resultativa con estar. Incluso se puede dar con un verbo como vigilar habitualmente utilizado para ejemplificar la lectura "pasiva no resultativa" por tratarse de un verbo de 'actividad'. Obsérvense, por ejemplo, los siguientes enunciados:

43. Nuestro funcionamiento está vigilado por la DGT y las autoridades sanitarias. Desconfíe, por tanto, de aquellos Centros que hacen "grandes descuentos". Los Centros de Conductores tenemos un compromiso con la Seguridad Vial.

44. Este servicio obtuvo en 2001 la Certificación de Calidad según la Norma EN-ISO 9002: 1994; y las cocinas la acreditación ISO 9001:2000. El comedor está vigilado por profesores del colegio, como parte del Programa de Acción Tutorial "Aprender a ser".

45. El aparcamiento de este establecimiento no está vigilado, por lo que LA CASONA DE LA REINA BERTA no responde de los objetos dejados en el interior de los vehículos, ni de los daños que pudieran sufrir estos.

Desde mi punto de vista al menos, estas construcciones con vigilar no denotan, como se considera propio de las "pasivas no resultativas" un "presente extendido" (alguien vigila X), una acción que se presenta como coexistente con el estado descrito por el participio (Bosque, 1999: 292) "che si mantiene stabile" "perché qualcuno continua ad operare su qualcosa" (De Miguel, 2001). Son construcciones que atribuyen al sujeto un rasgo valorativo que no procede solo del significado del verbo, sino que se puede inferir de nuestro conocimiento del mundo, y que establece un contraste evaluativo con otras entidades cuyo funcionamiento no ofrece las garantías que implica la propiedad de "estar vigilado por la DGT y las autoridades sanitarias", con otros comedores que "no están vigilados por profesores del colegio" o con otros aparcamientos que no se encuadran la categoría de los "no vigilados" con las diferencias respecto a la seguridad que se pueden inferir de ello.

En segundo lugar, si bien en las construcciones con verbos "bieventivos", de cambio, se atribuye, según se reconoce generalmente, una característica especificada por el verbo cuya interpretación no necesita "esfuerzo pragmático", con otros verbos -como sucedía con barrer, fregar, mordisquear - la propiedad no está reflejada en el significado mínimo asociado a la clase aspectual, sino que depende de otros componentes de significado más específicos y seguramente menos formalizados ${ }^{65}$; con otros, por último, la interpretación sí demanda "esfuerzo pragmático" en mayor o menor grado, en cuanto que la propiedad que

65 Ya en otros trabajos se ha hablado de la importancia que tienen en muchas parcelas del análisis lingüístico propiedades subléxicas específicas que algunos considerarían más enciclopédicas que lingüísticas, como las que en los planteamientos procedentes de Pustejovsky (1995) se incluyen en las estructuras de qualia o las que FrameNet incorpora a los marcos. Véase, por ejemplo, Martínez Linares $(2011,2012)$. 
atribuye al sujeto ni está especificada mediante algún tipo de rasgo subléxico, ni depende necesariamente del verbo; puede ser "activada" por los complementos y/o requerir ciertas inferencias que "may vary considerably and depend largely on our particular background knowledge and attitude" (Maienborn, 2009: 40-41).

Se podría concluir, pues, que, como afirma Maienborn (2009: 37) respecto de la "pasiva adjetiva" en alemán, la construcción de participio con estar ${ }^{66}$ es "a flexible gramatical means of creating a potentially new ad hoc property based on the verbal event"; pero cuál sea propiedad ${ }^{67}$, la relevancia del "estado" configurado por la construcción "can be provided by the participle itself, or it can be triggered by the inner- or extrasentential context" (Gese et al., 2009: 135), de manera que su "exact import, and therefore the place they occupy in the subject referent's property space, is more or less shaped by the context and by our contextually available world knowledge" (Maienborn, 2009: 41).

\section{Para finalizar}

De conformidad con los objetivos inicialmente planteados, a lo largo de este trabajo se han tratado algunos aspectos de las construcciones de sentido "resultativo" formadas por el verbo estar y un participio que cabe considerar problemáticos, según sugieren ya las diferencias de opinión sobre los rasgos que condicionan la viabilidad de estas construcciones o sobre la gramaticalidad de determinados enunciados.

Partiendo de las características "clásicas" atribuidas a las combinaciones "estar + participio" que se consideran "resultativas", se ha examinado, en primer lugar, el concepto de "estado resultante', clave en el análisis de estas construcciones; se ha mostrado que el término se usa frecuentemente de un modo impreciso y que de su empleo se infieren al menos dos sentidos relacionados a su vez con dos tipos de construcciones "resultativas" que, si bien pueden estar vinculadas $^{68}$, difieren en su interpretación y en sus condicionamientos.

Así se ha visto que los rasgos atributivos, "de caracterización”, que se asignan a construcciones "resultativas" como La barra está doblada, La ciudad está destruida, descansan en un concepto de "estado resultante" cualitativo, intensional, según el cual denota propiedades producto del proceso al que alude el verbo base del predicado.

Pero también se ha mostrado que, aunque algunos estudios han incluido en la misma clase enunciados del tipo La novela ya está leída, La cima ya está alcanzada, Los platos ya están fregados, asumiendo que denotan igualmente un "estado resultante", en realidad esta clase de construcciones no vehiculan el mismo significado atributivo, ni responden a los mismos condicionamientos, ni se les puede aplicar ese mismo sentido cualitativo, intensional, de "estado resultante". Antes bien, les subyace otro sentido más "temporal", asociado a la interpretación del "perfecto", que permite conceptuarlas como perífrasis de "fase": focalizan el estadio, la fase, subsiguiente a la conclusión del evento denotado por

66 La Academia (2009: 2215) también viene a reconocer que mediante la construcción "estar+participio" se crea sintácticamente la propiedad a partir del efecto causado por el proceso.

67 De hecho, como destaca Maienborn (2009: 41), un manuscrito al que se le atribuye estar escrito en una noche, como un cuadro del que se predique estar pintado por un niño, puede ser "either ingenious or awfully sloppy". 68 Véanse, entre otros, Gehrke (2012) y Maienborn (2009), a propósito de la relación entre ambas. Según Maienborn, por ejemplo, el participio estaría infraespecificado para una u otra lectura; correspondería a la pragmática proporcionar el valor "contextually suitable" que orientaría la lectura en una u otra dirección (2009: 44-46). 
el verbo- es decir, un 'estado resultante' en otro sentido del término-, que, además, suele encuadrarse en un marco de tareas que han de ser superadas; de ahí la frecuente presencia en este tipo de enunciados del adverbio de fase ya asociado tanto a la lectura del aspecto perfecto como a la expectativa que crea ese marco de tareas; las resultativas atributivas, por el contrario, ni requieren o implican ya, ni tampoco un guion "contextual" que proyecte una serie de fases que se han de culminar.

Se ha puesto de relieve, asimismo, que estas combinaciones de sentido más temporal no se hallan circunscritas a verbos que incorporan en su estructura léxica un "estado resultante" en su sentido más restrictivo; se construyen de hecho con verbos de clases distintas, incluso con verbos como besar, cantar, cruzar, frecuentemente señalados como inadecuados para las formaciones resultativas por su significado; solo se necesitan condiciones contextuales que permitan incluir el evento denotado en "some implicit frame concerning one or more supposed or scheduled tasks" (Bosque, 2014: 69).

En cuanto a las atributivas - como La puerta está abierta, La casa está bien construida-, no se pone en tela de juicio la desfocalización del evento en que se sustenta su condición estativa, ni tampoco el hecho de que los verbos bieventivos de cambio, con un evento causativo de acción y un evento resultativo de estado, sean los más capacitados para formar construcciones que asignan al sujeto propiedades interpretables sin "esfuerzo pragmático". Pero sí se ha hecho hincapié en que la interpretación "cualitativa” propia de esta clase de construcción está mucho más extendida de lo que podrían predecir las explicaciones clásicas basadas en rasgos aspectuales. Según se ha visto, la propiedad atribuida no solo puede provenir del significado lexicalizado por el verbo; puede derivar de otras facetas más enciclopédicas del contenido de las unidades verbales que permiten construir un "efecto" más o menos perceptible en la entidad afectada por el proceso -como El piso está fregado-, o puede ser una propiedad no perceptible, más sutil, inmaterial, con un componente evaluativo o valorativo configurado a partir de inferencias dependientes del conocimiento del mundo "contextually available" y/o de "otros materiales", como los complementos con por alusivos a un agente que o bien deja una "huella" visible de su participación o bien tiene un "impacto" valorativo que aporta ese componente cualitativo requerido por la construcción: La comida está preparada por verdaderos expertos, El material está revisado por especialistas, La medalla está besada por el Papa.

Como se admitía al principio, aún queda mucho por analizar en el campo de las construcciones grosso modo resultativas formadas mediante un participio y el verbo estar. Bosque (2014: 69), por ejemplo, señalaba recientemente que no había podido encontrar en la bibliografía sobre estas construcciones muchas referencias al factor "efecto fasal" tan vinculado al uso de ya; en cuanto a las atributivas, si bien se admite que el evento denotado por el predicado ha de tener un efecto que se pueda medir o evaluar, no parece fácil sistematizar cuándo y cómo se configura un efecto que se pueda medir o evaluar. Pero sí se habrá comprobado que ninguna de las dos lecturas que se pueden diferenciar en el grupo de las construcciones resultativas relacionadas con dos sentidos de "estado resultante" se hallan constreñidas a verbos que lexicalizan un estado resultante ni pueden explicarse partiendo solo de clases aspectuales o de factores estrictamente gramaticales, sin tomar en consideración aspectos pragmáticos y contextuales ${ }^{69}$.

69 De hecho, como sugería recientemente Levin (2015), la relevancia de esos aspectos pragmáticos y contextuales va dejando su impacto en la evolución de las investigaciones sobre materias circunscritas inicialmente al dominio sintáctico. 


\section{Referencias bibliográficas}

Alexiadou, A. (2005): "A note on non-canonical passives: the case of the get passive", en Broekouis, H. et al. (eds.): Organizing Grammar: Linguistic Studies in Honor of Henk van Riemsdijk, Berlin, Mouton de Gruyter, pp. 13-21.

Batiukova, O. (2006): "Las oraciones medias como proyección de estructuras subléxica", en Villayandre Llamazares, M. (ed.): Actas del XXXV Simposio Internacional de la Sociedad Española de Lingüística, León, Universidad de León, pp. 221-241. http://www3. unileon.es/dp/dfh/SEL/actas.htm

Bosque, I. (1990): "Sobre el aspecto en los adjetivos y en los participios", en Bosque, I. (ed.): Tiempo y aspecto en español, Madrid, Cátedra, pp. 177-211.

Bosque, I. (1999): "El sintagma adjetival. Modificadores y complementos del adjetivo", en Bosque, I. y V. Demonte (dirs.): Gramática descriptiva de la lengua española, Madrid, Espasa, pp.217-310.

Bosque, I. (2014): “On Resultative Past Participles in Spanish”, Catalan Journal of Linguistics, Vol. 13, pp. 41-77 http://revistes.uab.cat/catJL/article/view/v13-bosque/155-pdf-en [21-03-2015].

Bruening, B. (2012): "Word Formation is Syntactic: Adjectival Passives in English" http:// udel.edu/ bruening/Downloads/AdjectivalPass3.pdf [15-12-2014]

Bruhn de Garavito, J. y E. Valenzuela (2008): "Eventive and stative passives in Spanish L2 acquisition: A matter of aspect", Bilingualism: Language and Cognition, 11, 3, pp. 323-336.

Conti, C. (2004): “Construcciones pasivas con estar”, Estudios de Lingüística, 18, págs. 21-44.

Delbecque, N. (2006): “Ya: Aclaración cognitiva de su uso y función”, Revista Española de Lingüística,36, pp. 43-71.

De Miguel, E. (2001): "Relazioni tra il lessico e la sintassi: classi aspettuali di verbi ed il passivo spagnolo", Círculo de Lingüistica Aplicada a la Comunicación, 8. Publicado en Simone, R. (ed), Studi Italiani di Linguistica Teorica e Applicata, 2000, 29.2, 201-217. http://www.ucm.es./info/circulo/no8/demiguel.htm

De Miguel, E. (2004): “Qué significan aspectualmente algunos verbos y qué pueden llegar a significar”, en Cifuentes Honrubia, J. L. y C. Marimón Llorca (eds.): Estudios de Lingüística: el verbo, Alicante, Universidad de Alicante, pp. 167-206.

Embick, D. (2004): "On the Structure of Resultative Participles in English", Linguistic Inquiry, VOL. 35, No 3, PP. 355-392.

Embick, D. (2009): Roots, states, stative passives. Handout for Roots workshop; Stuttgart, Universidad de Stuttgart, http://www.ling.upenn.edu/ embick/stut.pdf [12-01-2015]

Escandell, M. V. y M. Leonetti (2002): “Coercion and the Stage/Individual Distinction”, en Gutiérrez Rexach, J. (ed.), From words to discourse, Amsterdam, Nueva York, Elsevier, pp. 159-179.

Fábregas, A. y R. Martín (2012): "Syntactic and semantic properties of Davidsonian state verbs “, 42 Linguistic Symposium Romance Languages, University of SouthernUTAH.

https://www.academia.edu/1722270/Syntactic_and_semantic_properties_of_Davidsonian_ state_verbs [15-10-2014]

Fernández, A., Vázquez, G. y Martí, M.A. (2002): “Alternancias diatéticas relacionadas con el aspecto", Verba, 29, pp. 389-402. 
Fernández Leborans, M. J. (1999): “La predicación. Las oraciones copulativas”, en Bosque, I. y V. Demonte (dirs.): Gramática descriptiva de la lengua española, Madrid, Espasa, pp. 2357-2460.

Fernández Ramírez, S. (1986): Gramática española. 4. El verbo y la oración, vol. ordenado por I. Bosque, Madrid, Arco Libros.

García Fernández, L. (1995): "La interpretación temporal de los tiempos compuestos", Verba, 22, pp. 363-396.

García Fernández, L. (1999): “Los complementos adverbiales temporales. La subordinación temporal", en Bosque, I. y V. Demonte (dirs.): Gramática descriptiva de la lengua espanola, Madrid, Espasa, pp. 3129-3208.

Gehrke, B. (2012): "Passive states", en Demonte, V. y L. McNally (eds.): Telicity, Change and State. A Cross-Categorial Viev of Event Structure, Oxford, Oxford University Press, pp. 185-211.

Gehrke, B.y C. Marco (2014): "Different by-phrases with adjectival and verbal passives: Evidence from Spanish corpus data", Lingua, 149, pp. 188-214: https:/www.academia.edu/8682251/Different_by-phrases_with_adjectival_and_verbal_passives_Evidence_from_Spanish_corpus_data (03-03-2015).

Gese, H. (2011): "Events in adjectival passives", en Reich, I., E. Horch y D. Pauly (eds.): Proceedings of Sinn un Bedeutung 15, Saarbrucken, Universaar-Saarland University Press, pp. 259-273.

Gese, H., B. Stolterfoht, C. Maienborn (2009): "Context Effects in the Formation of Adjectival Resultatives”, en Winkler, S. y S. Featherston (eds.): The Fruits of Empirical Linguistic: Vol 2, Berlin, De Gruyter, pp. 125-155.

Girón Alconchel, J. L. (1991): Tiempo, modalidad y adverbio, Salamanca, Universidad de Salamanca.

Goldberg, A. y F. Ackerman (2001): "The pragmatics of obligatory adjuncts", Language, 77, no 4, pp. 798-814.

Gómez Torrego, L. (1988): Perifrasis verbales, Madrid, Arco Libros.

Hengelved, K. (1986): “Copular verbs in a functional grammar of Spanish", Linguistics, 24, pp. 393-420.

Jiménez Peña, S. y y Rodríguez Sellés (2002): “AAgentes causantes?”, en González Pereira, M. Souto Gómez y A. Veiga Rodríguez (coords.): Léxico y gramática [Selección de ponencias e comunicación presentadas no Congreso Internaciona de Lingüística "Léxico \& Gramática" celebrado na Facultade de Humanidades de Lugo do 25 ó 28 de setembro de 2000], pp. 215-224.

Jurado Salinas, M. (2000): "Las construcciones pasivas con ser y estar", Número Especial. Ed. R. Maldonado Soto. Revista Española de Lingüística Aplicada, pp. 175-191.

Kratzer, A. (2000): "Building statives", Proceedings of the Twenty-Sixth Annual Meeting of the Berkeley Linguistic Society: General Session and Parasession on Aspect, Vol $26 \mathrm{n}^{\circ}$ 1, pp. 385-399. http://elanguage.net/journals/bls/article/view/3344/3331

Levin, B. (2009): "Lexical Semantics of Verbs IV; Aspectual Approaches to Lexical Semantics Representation", Course LSA 116. http://web.stanford.edu/ bclevin/lsa09aspapp.pdf [23-03-2014]

Levin, B. (2015): "Semantics and Pragmatics of Argument Alternations", Annual Review of Linguistics, 1, pp. 63-83. 
Levin, B. y M. Rappaport Hovav (1991): "Wiping the slate clean: A lexical semantic exploration”, en Levin, B. y S. Pinker, (eds.) (1991): Lexical and Conceptual Structure, Oxford, Blackwell, págs.123-151

Levin, B. y M. Rappaport Hovav (2005): Argument Realization, Cambridge, Cambridge University Press.

Levin, B. y M. Rappaport Hovav (2013): "Lexicalized meaning and manner/result complementariry", en Arsenijevic, B., B. Gehrke y R. Marín (eds.); Studies in the composition and decomposition of event predicates, Springer, Dordrecht, pp. 49-70.

Maienborn, C. (2009): "Building Event-Based Ad Hoc Properties: On the Interpretation of Adjectival Passives”, en Riester, A. y T. Solstad (eds.): Proceedings of Sinn und Bedeutung, 13, Stuttgart, University of Stuttgart, pp. 35-49.

Marín, R. (2000): El componente aspectual de la predicación, Tesis doctoral, Departament de Filologia Espanyola, Universitat Autònoma de Barcelona.

Marín, R. (2004): Entre ser y estar, Madrid, Arco Libros.

Martínez Linares, M. A. (2011): “On protagonizar 'an event' and the scope of the concept of light verb”, en Cifuentes Honrubia, J. L. y S. Rodríguez Rosique, Spanish Word Formation and Lexical Creation, Amsterdam/Philadelpia, John Benjamins, pp. 185-216.

Martínez Linares, M. A. (2012): “Aznarizar, zapaterizar... En torno a verbos formados sobre nombres propios con el sufijo -izar”, LEA, XXXIV/2, pp. 247-274.

Mendikoetxea, A. (1999): “Construcciones inacusativas y pasivas", en Bosque, I. y V. Demonte (dirs.), Gramática descriptiva de la lengua española, Madrid, Espasa, pp. 15751629.

Morimoto, Y. (1998): El aspecto léxico: delimitación, Madrid, Arco Libros.

Nishiyama, A. y J. P. Koening (2010): "What is a perfect state", Language, 86, n 3, pp. 611-646.

Parsons, T. (1990): Events in the Semantics of English. A Study of Subatomic Semantics, Cambridge,Mass., MIT Press.

Pustejovsky, J. (1991): “The syntax of event structure”, en Levin, B. y S Pinker (eds.): Lexical and Conceptual Structures, Oxford, Blackwell, pp. 47-81.

Pustejovsky, J. (1995): The Generative Lexicon, Cambridge, Mass., MIT Press

Rapp, I. (2001): "The attributive past participle. Structure and temporal interpretation", en Féry, C. y W. Sternefeld (eds.): Audiatur Voz Sapientiae. A Festschrift for Arnim von Stechow, Berlín, Academie-Verlag, pp. 392-409.

Rappaport, M. (2008): "Lexicalized meaning and the internal temporal structura of events", en Rothstein. S. (ed.): Theoretical and crosslinguistics approaches to the semantic of aspect, Amsterdam, John Benajmins, pp. 13-42.

Real Academia Española (2009): Nueva gramática de la lengua española, 2 vols., Madrid, Espasa.

Tenny, C. L. (1987): Grammaticalizing aspect and affectedness, Tesis doctoral, Department of Linguistics and Philosophy, MIT.

Vázquez, G., A. Fernández y M. A. Martí (2000): Clasificación verbal. Alternancias de diátesis, Lleida, Universitat de Lleida.

Vázquez, G. y A. Fernández (2003): “Interpretación semántica de esquemas sintácticos”, $R L A, 41$, pp. 143-169.

Wilk-Racieska, J. (2012): "Esbozo del estudio de las funciones semántico-pragmáticas de ya", ELUA, 26, pp. 383-404. 
Yllera, A. (1999): "Las perífrasis verbales de gerundio y participio", en Bosque, I. y V. Demonte (dirs.): Gramática descriptiva de la lengua española, Madrid, Espasa, pp. 3391-3443.

\section{Anexo}

1. http://www.eluniversodeloslibros.com/2013/10/nuevas-lecturas-septiembre.html

2. http://archivosdelvalhalla.blogspot.com.es/2012/11/imm-noviembre.html

3. http://www.mediavida.com/foro/32/us-open-2010-393924/42

4. http://davidmalabarista.blogspot.com.es/2012/11/mondarruego-por-la-faja-de-la-escuzana.html

5. http://www.gsmspain.com/foros/su3488652_u66622_p3_mensajes-usuario-aristos.html

6. http://www.diarioinformacion.com/universitarios/2011/10/18/formamos-profesionalescontexto-sociedad-digital/1179944.html

7. http://www.desdelasgradas.com.mx/imprimir.php?id_n=1110

8. http://www.experimentosconazucar.com/2011/11/poniendo-el-pino.html

9. http://boscodigresiones.blogspot.com.es/2008/09/amanece-lloviscando-fotografas-delotoo.html

10. http://torreschava.blogspot.com.es/2010/11/domingo-7-de-noviembre-dia-d.html

11. http://www.panageos.es/gente-grabada-sin-saberlo

12. http://unosetentaydos.mforos.com/1631430/10149309-infanteria-alemana-1-72-hasegawa/

13. http://www.rankia.com/foros/bolsa/temas/1078368-encuesta-margrave-cuanto-dineronecesitas-para-vivir-trabajar-ser-feliz?page $=1402$

14. http://www.foromtb.com/showthread.php/646673-Quebrantahuesos-2011/page41

15. https://books.google.es/books?id=zahkJUpUOqoC\&pg=PA197\&lpg=PA197\&dq=\%2 2 cuando + un + discurso + est $\% \mathrm{C} 3 \% \mathrm{~A} 1+$ memorizado $\% 22 \&$ source $=$ bl\&ots $=$ fTiHIIwEW A\&sig=ZBUYRExhK_-7picyZGVis8MtZRw\&hl=es\&sa=X\&ei=ECNsVeHZAYrzUO $7 \mathrm{Ig}-\mathrm{gO} \& \mathrm{ved}=0 \mathrm{CCEQ} 6 \mathrm{AEwAA} \# \mathrm{v}=$ onepage $\& \mathrm{q}=\% 22$ cuando $\% 20 \mathrm{un} \% 20$ discurso $\% 20$ est $\% \mathrm{C} 3 \% \mathrm{~A} 1 \% 20$ memorizado $\% 22 \& \mathrm{f}=$ false

16. http://in-a-words.blogspot.com.es/2012/01/no-podia-pisar-en-la-cocina.html

17. http://www.indemnizacionaccidentes.org/Indemnizacion-por-caida./9

18. ht tp://www.biblegateway.com/pas sage/? search=Lucas $+11 \% 3 \mathrm{~A} 14$ 28\&version=RVR1960;LBLA;NTV;NVI;TLA

19. http://drabada.blogspot.com.es/2012/03/atapuerca-mentiras-y-evolucion-humana.html

20. http://www.es.scribd.com/doc/86143747/Comunicacion-en-imagenes

21. http://mutuocentro.com/molecula-producto/

22. http://www.pioneerpump.co.uk/es/markets/oil-gas.htm

23. http://www.tripadvisor.es/ShowUserReviews-g198524-d1597128-r181115459-Hotel_ Imbery-Hinterzarten_Black_Forest_Baden_Wurttemberg.html

24. http://www.tripadvisor.es/ShowUserReviews-g186258-d1128719-r124146855-Thai_in_ the_Park-Plymouth_Devon_England.html

25. http://www.tripadvisor.es/SimilarHotelsPopunder?MTPU_RULE=287\&onclick=1

26. http://www.patagonia4x4.com.ar/phpbb3/viewtopic.php?t=42509\&p=447110

27. http:/eljuntaletrascom.wordpress.com/2012/09/04/fauna-humana-26-el-modenno/

28. http://elcamionerorecomienda.blogspot.com.es/2010/02/ciudad-real.html 
29. http://www.unblogparacomerselo.com/?p=1677

30. http://www.minube.com/rincon/la-eritana-a690681

31. http://www.emeraldinsight.com/portal/es/products/collections.htm

32. http://www.nicetales.com/preguntas-frecuentes

33. http://www.gartoo.es/fotos-piso-piloto-amueblado

34. http://mundojardin.portalmundos.com/un-apartamento-en-madrid-decorado-por-tomasalia

35. http://valdeperrillos.com/book/export/html/4354

36.http://www2.pelayo.com/opinion/noticias.htm

37. http://www.alhambrasl.com/index.php?option=com_content...

38. http://www.lavanguardia.com/fotos/20120420/54284654092/el-cartel-de-la-ii-fira-d-artesta-disenado-por-josep-serra-del-estudio-mensula-es-un-homenaje-al.html

39. https://fr33ky.wordpress.com/2012/07/25/disfruta-del-batimovil-y-el-batpod-en-vivo-ya-todo-color/

40. http://www.stjosephpublications.com/book_manuscripts_pages/testimonies/113\%20 -\%20Lucio\%20Rodrigo, \%20S.J.\%27s\%20Story\%20Following\%20the $\% 20$ Letters $\% 20$ from $\% 20 J a n u a r y \% 2018, \% 201967 . h$ tm

41.http://es-la.facebook.com/permalink.php?story_fbid=190670287684356\& $\mathrm{id}=23858888287188$

42. http://www.terra.es/personal5/felix.pascual/Pag.28.htm

43. http://www.renovarcarnetdeconducir.com/nuestra-garantia/

44. http://www.sek.es/index.php?section=colegios/santa-isabel/servicios

45. http://www.lacasonadelareinaberta.com/tarifas-y-reservas.html 